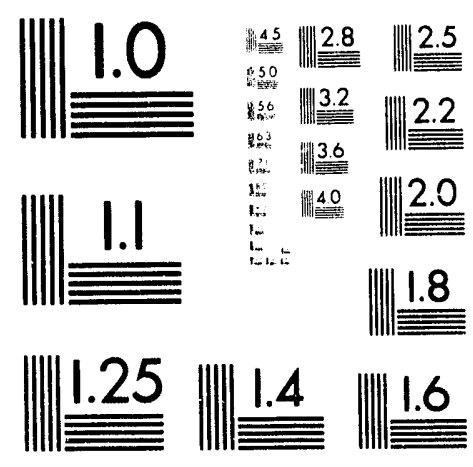



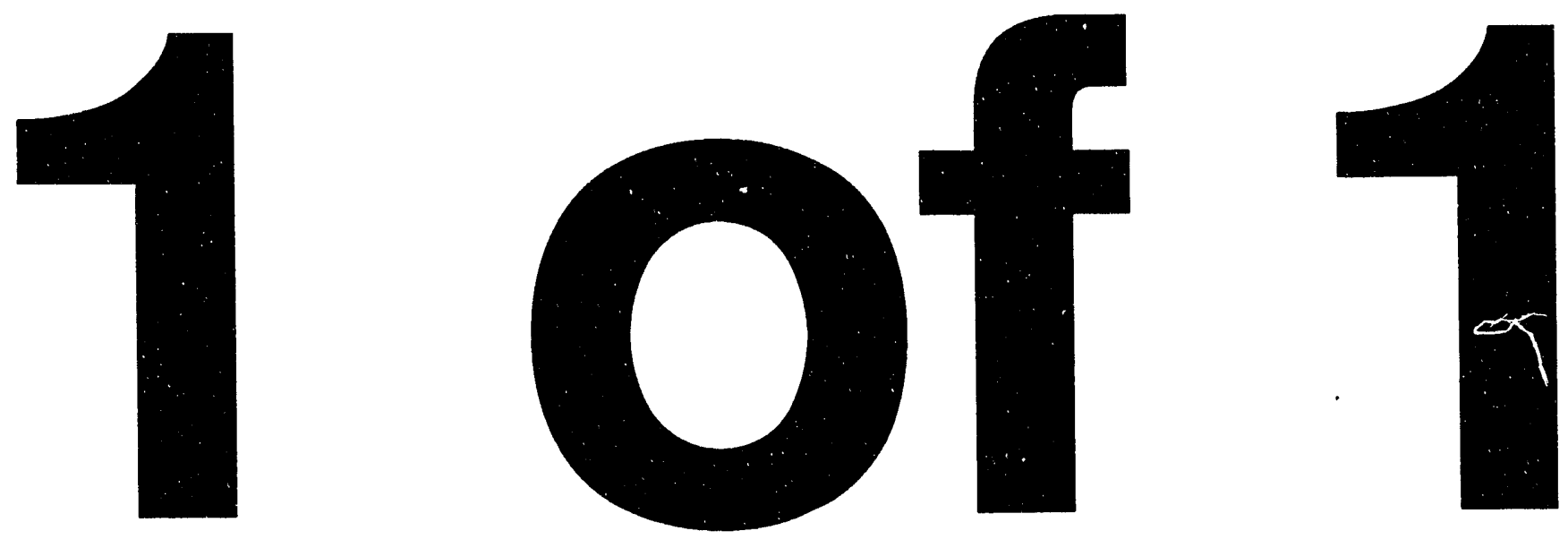
SAND92-1381

Distribution

Unlimited Release

Category UC - 235

Printed February 1993

\title{
Testing and Evaluation of Large-Area Heliostats for Solar Thermal Applications
}

\author{
John W. Strachan \\ Richard M. Houser \\ Solar Thermal Test Department \\ Sandia National Laboratories \\ Albuquerque, New Mexico 87185
}

\begin{abstract}
Two heliostats representing the state-of-the-art in glass-metal designs for central receiver (and photovoltaic tracking) applications were tested and evaluated at the National Solar Thermal Test Facility in Albuquerque, New Mexico from 1986 to 1992. These heliostats have collection areas of 148 and $2(1) \mathrm{m}^{2}$ and represent lowcost designs for heliostats that employ glass-metal mirrors. The evaluation encompassed the performance and operational characteristics of the heliostats, and examined heliostat beam quality, the effect of elevated winds on beam quality, heliostat drives and controls, mirror module reflectance and durability, and the overall operational and maintenance characteristics of the two heliostats. A comprehensive presentation of the results of these and other tests is presented. The results are prefaced by a review of the development (in the United States) of heliostat technology.
\end{abstract}




\section{ACKNOWLEDGMENTS}

The authors are indebted to Jake VanDerGeest for his enthusiastic and tireless assistance in the testing and evaluation of the prototype heliostats. We are grateful to Daniel Alpert who guided our efforts and provided invaluable assistance in the interpretation of our test results, including the performance of HELIOS code simulations of collector performance. Our thanks also go to Bob Edgar, Sam Dunkin, "JJ" Kelton, Larry Yellowhorse, and Winn Erdman for their assistance in numerous technical tasks. The manufacturers of the large-area heliostats provided valuable technical support and many useful suggestions

throughout the evaluation period; we thank David Gorman (Advanced Thermal Systems, Inc.) and Daryl Bielenberg (Solar Power Engineering Company, Inc.). 


\section{CONTENTS}

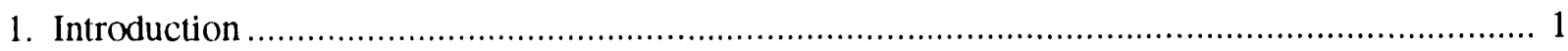

Background on Heliostat Technology Development .............................................. 1

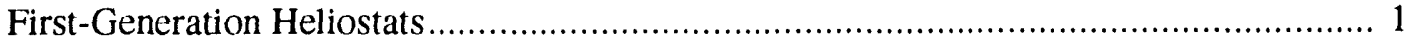

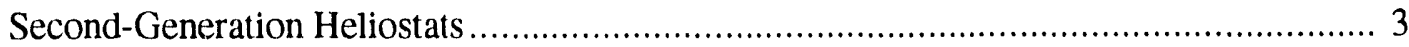

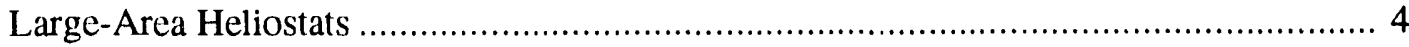

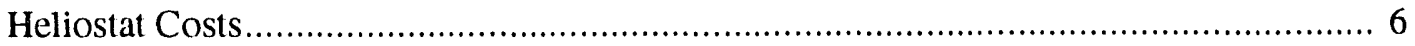

Objectives and Scope of the Evaluation of the Large-Area Heliostats............................... 7

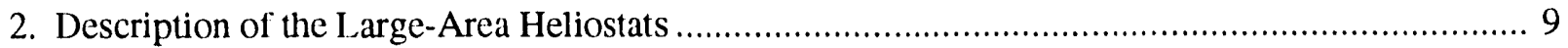

Second-Generation Heliostat Design Specifications ............................................ 9

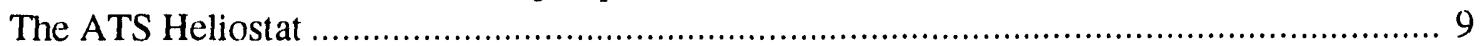

The SPECO Heliostat....................................................................................... 10

Mirror Focal Length and Heliostat Canting Range ............................................... 11

?. Testing and Evaluation of the Large-Area Heliostats................................................ 13

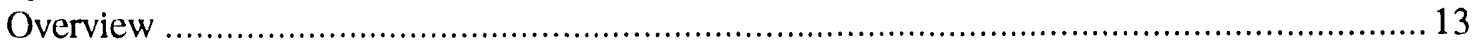

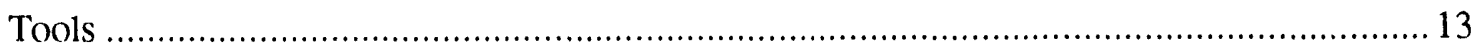

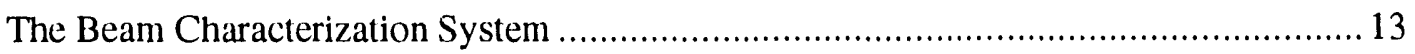

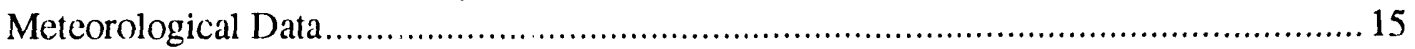

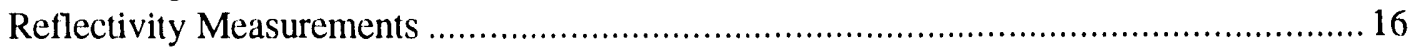

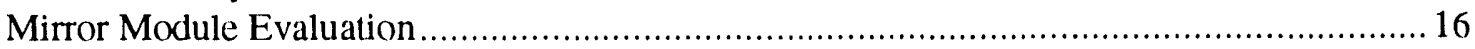

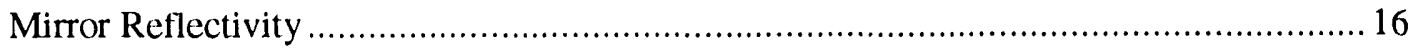

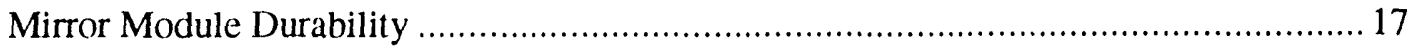

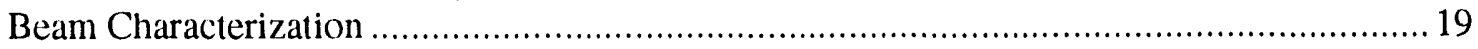

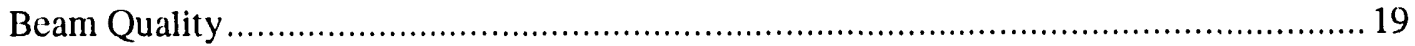

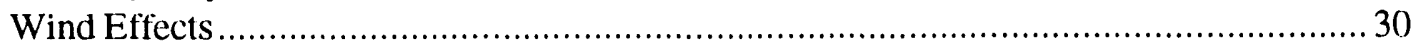

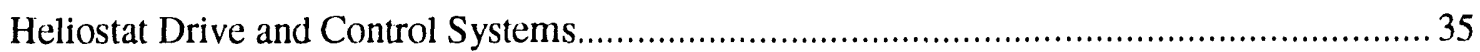

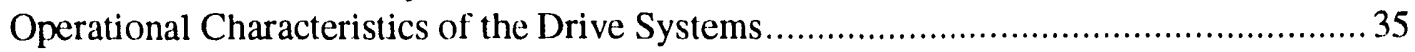

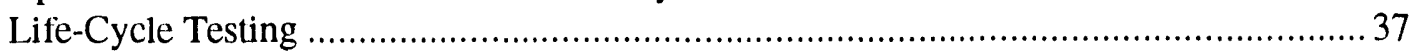

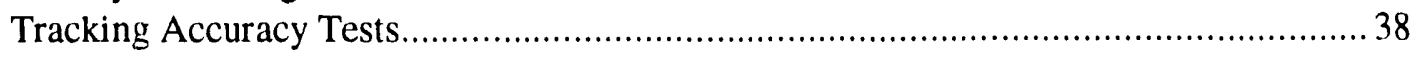

Failure and Remanufacture of the SPECO Drive ........................................... 40

Failure and Modification of the Low-Cost Heliostat Drive ...................................40

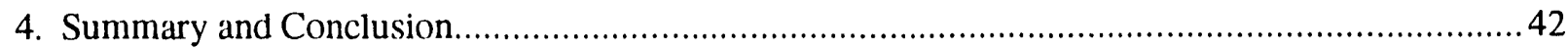

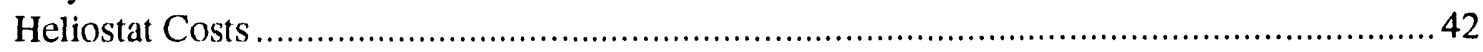

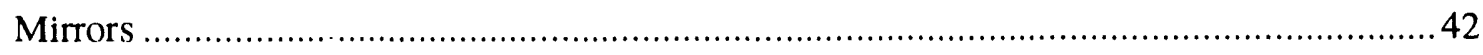

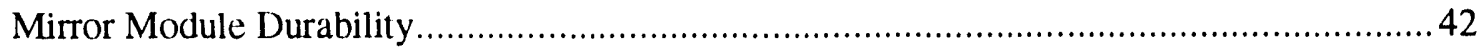

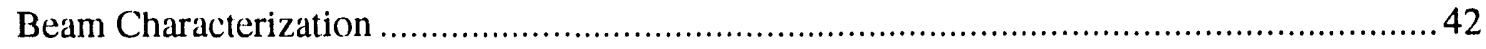

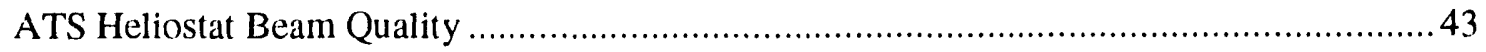

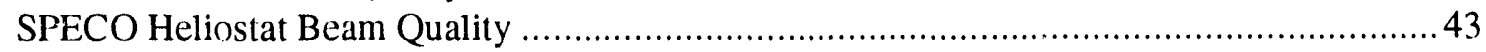

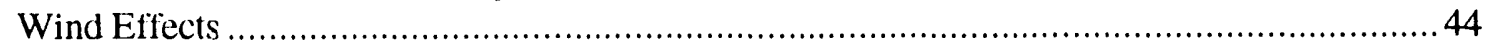

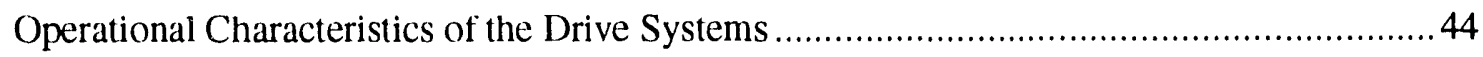

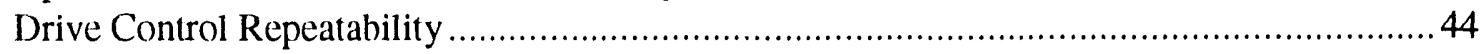

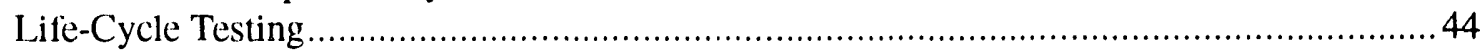


All-Day Tracking 45

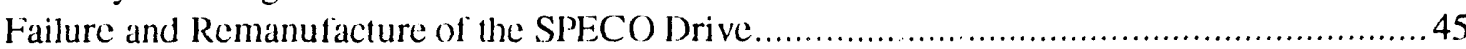

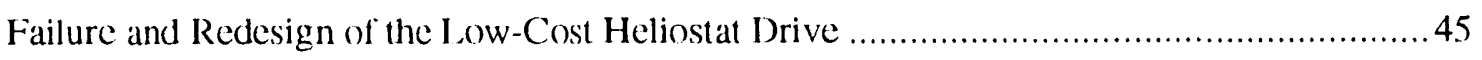

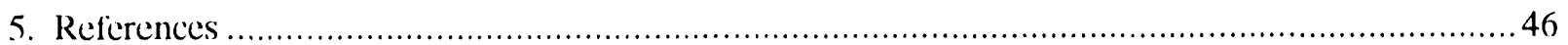

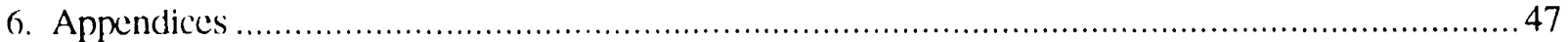

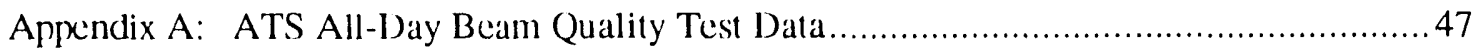

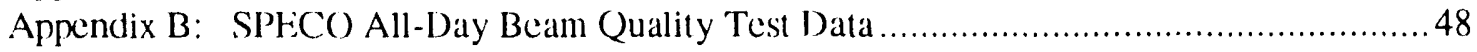

Appendix C: Normalization Procedure for Comparison of Beam Quality

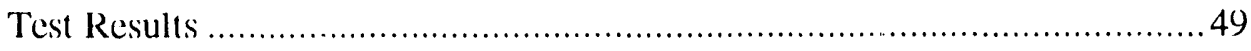

Appendix 1): Analysis of Measurement Error in the Beam Characterization

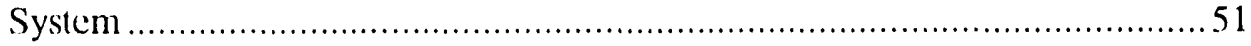

Appendix E: Determining the Solar Average Specular Reflectivity of a

Collector Mirror 


\section{FIGURES}

Figure 1. Front View of the Large-Area Heliostats........................................................ 1

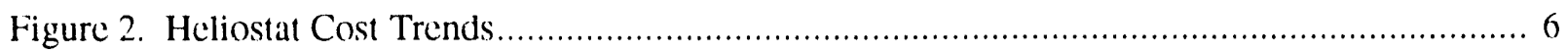

Figure 3. Rear View of ATS Heliostat ............................................................................. 9

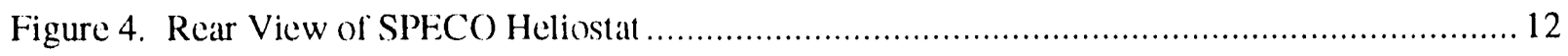

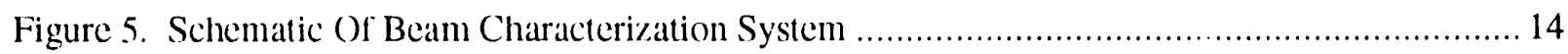

Figure 6. Long-Term Reflectivity of Large-Area Heliostat Mirrors ........................................... 17

Figure 7. Effects of Soiling on the Reflectivity of the ATS Heliostat .......................................... 18

Figure 8. Contour Plots of ATS Heliostat Beam on August 26, 1991 ...................................... 21

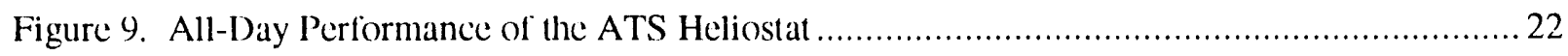

Figure 10. Contour Plots of SPECO Heliostat Beam............................................................. 23

Figure 11. All-Day Performance of the SPECO Heliostat .................................................. 24

Figure 12. Comparison of the Beam Power of the ATS and SPECO ....................................... 25

Figure 13. Comparison of Peak Power and Beam Diameters of the ATS and SPECO....................25

Figure 14. ATS and SPECO Beam Power Normalized in Terms of Mirror Reflectivity ................. 26

Figure 15. Comparing Measured and Predicted Beam Profiles for the ATS Heliostat ..................... 28

Figure 16. Comparing Measured and Predicted Beam Profiles for the SPECO Heliostat.................29

Figure 17. Polar Plot of Beam Centroid Movement ................................................................ 32

Figure 18. Effect of Wind on ATS Heliostat Beam Position ................................................. 34

Figure 19. Effect of Wind on SPECO Heliostat Beam Position .................................................. 34

Figure 20. Comparison of Linea Curve Fits of Wind Effects Results ........................................ 35

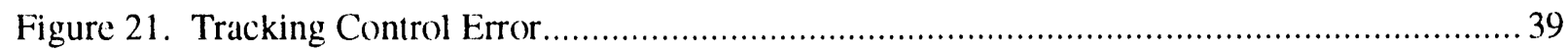




\section{TABLES}

Table 1. Second-Generation Heliostat Design Requirements ............................................ 4

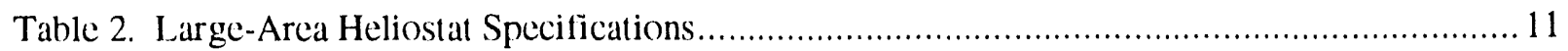

Table 3. Measured Beam Characteristics of ATS Heliostat ....................................................... 22

Table 4. Measured Beam Characteristics of SPECO Heliostat .............................................. 24

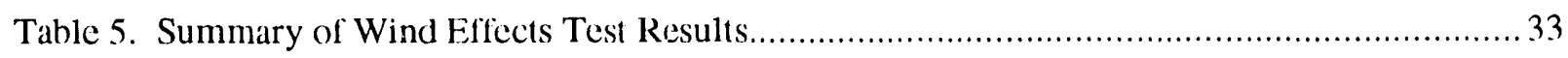

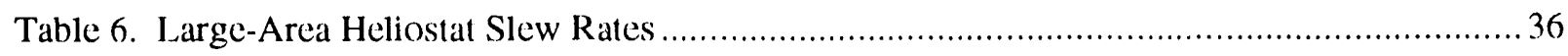

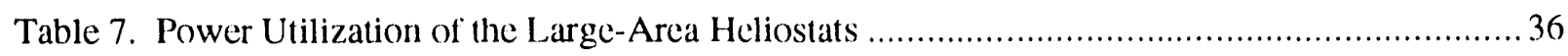

Table 8. Large-Area Heliostat Drive Control Repeatability ................................................... 37

Table 9. Summary of Life Cycling Data for Large-Area Heliostats ........................................... 38

Table 10. ATS All-Day Beam Quality Test Results....................................................... 47

Table 11. SPECO All-Day Beam Quality Test Results ...................................................... 48

Table 12. Estimates of BCS Error for Heliostats and Dish Concentrators Measurements.................53 


\section{INTRODUCTION}

\section{Background on Heliostat Technology Development}

Large-area, glass-metal heliostats have collection areas in the range of 100 to 20() $\mathrm{m}^{2}$; they are the culmination of more than 10 years of development of commercial heliostats for solar thermal central receiver technology and represent the lowest cost glass-metal heliostat technology developed to date (see Fig. 1).

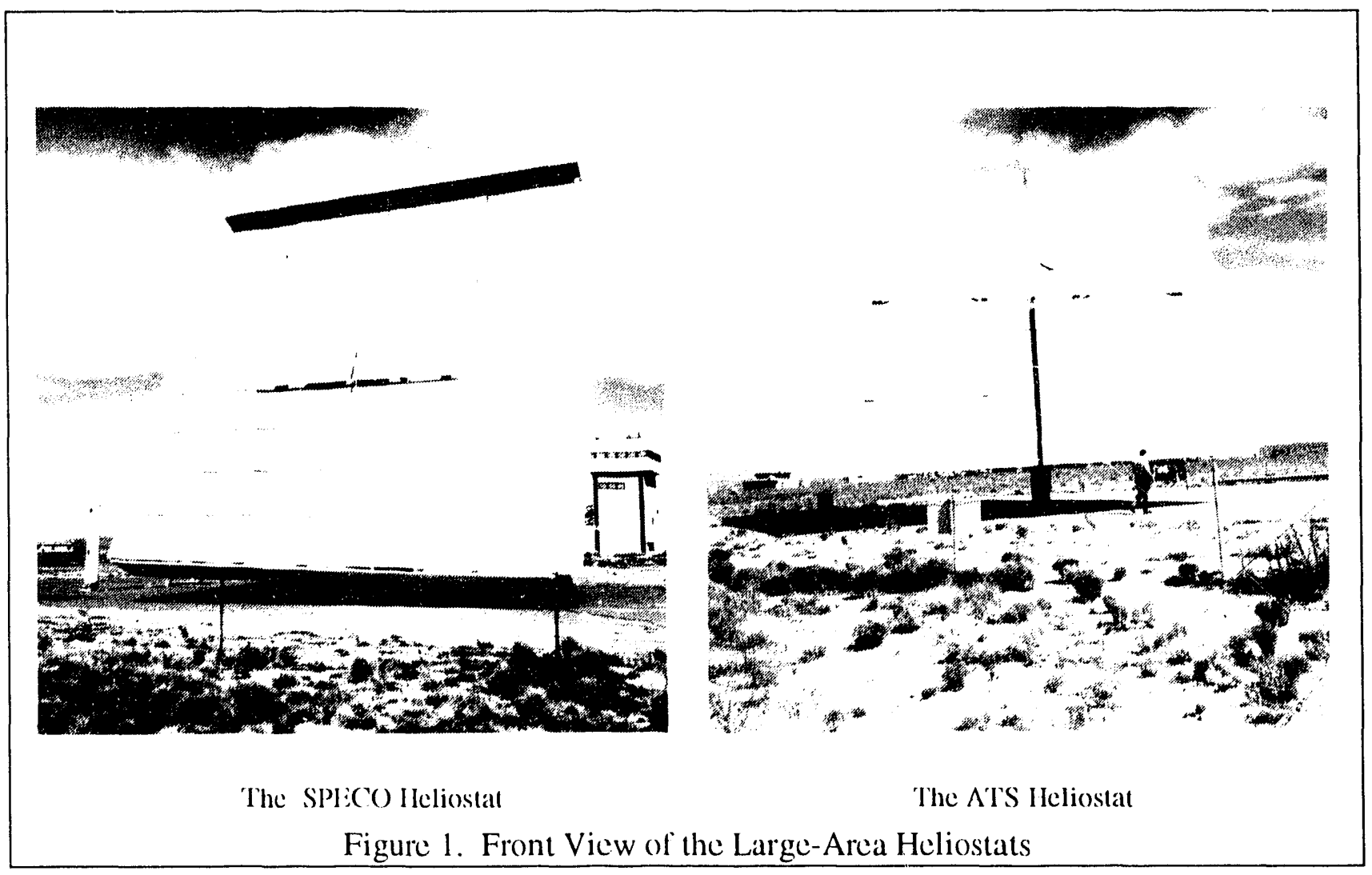

\section{FIRST-GENERATION HELIOSTATS}

The recent history [1] of heliostat development under the sponsorship of the United States Department of Energy (DOF) began in 1975 with the Pilot Plant System Research Experiment. The heliostat design effort, which was carried out by three US contractor teams led by Martin Marietta Corporation, McDonnell Douglas Astronautics Company, and Honeywell, Inc.,' produced the lirst-generation prototype heliostats

\footnotetext{
${ }^{1}$ Although not detailed here, this research effort explored the development of dome-enclosed heliostats using mirror modules made of aluminized or silvered plastic membranes. Teams led by Bocing Inngineering and Construction Co., as well as General Electric, developed designs, and Bocing built four $48-\mathrm{m}^{2}$ prototypes.
} 
ranging in size from 37 to $41 \mathrm{~m}^{2}$ of mirrored collection area. The basic heliostat design features that emerged from this effort and were carried forward into succeeding designs included:

- Mirrors made from laminated glass or from a composite (sandwich) of glass and a styrofoam (honeycomb) core. (The laminated glass design proved itself over time to be the better choice.)

- A metal framework upon which one or more mirrors were mounted to form a mirror module.

- An overall metal structure or frame to support the mirror modules. This frame attached to the heliostat drive system.

- A two-axis drive that permitted rotation of the solar collector in elevation (up-down) and in azimuth (east-to-west) combined in one unit.

- A cylindrical pedestal to support the mirror modules, their support structure, and the heliostat drive system.

In a top-to-bottom descriptive sequence 1) mirrors are joined to form mirror modules, 2) mirror modules are bolted or bonded to a support structure, 3) the support structure is welded or bolted to an elevation drive assembly, 4) the elevation drive assembly is joined to the azimuth drive, 5) the azimuth drive is set atop the heliostat pedestal, and 6) the pedestal is set into or onto a concrete foundation.

In 1977. Martin Marietta was awarded a contract to manufacture and install 220 heliostats to serve as the heliostat field for the Central Receiver Test Facility (CRTF) in Albuquerque, New Mexico. ${ }^{2}$ The design of these heliostats was customized to meet the changing needs of a test facility: the mirrors they employed were adjustable and smaller than those of Martin Marietta's first-generation design, and the total heliostat area was also smaller $\left(37.2 \mathrm{~m}^{2}\right.$ versus $\left.40 \mathrm{~m}^{2}\right)$.

In mid-1978, Martin Marietta and McDonnell Douglas were contracted to develop competitive designs for Solar I, a 1()-MW pilot solar thermal (central receiver) electric power plant built in Barstow, California. Prototype heliostats were evaluated at Sandia's CRTF, and Martin Marietta was subsequently (1980-81) awarded the contract to manufacture 1,911 lirst-generation heliostats and install 1,818 of them in the Solar I plant. The remaining 9.3 heliostats were for installation at the European solar thermal test facility in Almeria, Spain. The design of these heliostats incorporated improvements in both the mirror modules and the drive mechanisms, the need for which had been identified in the test and evaluation phase of the DOE Pilot Plant System Research Experiment.

\footnotetext{
${ }^{2}$ The facility is known today as the National Solar Thermal Test Facility (NSTTF).
} 


\section{SECOND-GENERATION HELIOSTATS}

A second round of DOE-sponsored heliostat development took place between 1977-1981. First, with the goal of reducing the cost of the first-generation heliostats, a series of component design studies was carried out by four US companies (Bocing, General Electric, McDonnell Douglas, and Solaramics) [2]. An important result of that study was the identilication of superior heliostat design approaches, approaches that were mature, well analyzed and tested, and carried a minimum risk.

Beginning in 1979, contracts were issued to design and build prototype heliostats that would be tested by a national laboratory (Sandia National I aboratories, herealter referred to as Sandia) and to develop detailed plans and cost estimates for the low-cost, mass manufacture, assembly, installation, and maintenance of heliostats. Five US companies (ARCO, Bocing, Martin Marietta, McDonnell Douglas, and Westinghouse ${ }^{3}$ ) participated in this effort. The resulting second-generation glass-metal heliostats were a step larger than the first generation and ranged in size from $44 \mathrm{lo} 57 \mathrm{~m}^{2}$. These heliostats were subjected to thorough testing at the CRTF. An important technical result of this effort was the definition of heliostat design specifications, which include a) operational modes, b) optical performance, e) survival, and d) a 3()-year life [1]. These specilications are reprinted in Table 1.

A follow-on effort was carried out by Martin Marietla and McDonnell Douglas, which sought to further reduce heliostat costs by identifying justifiable changes to either the heliostat design specifications or the specified environmental conditions. Some of the significant lindings/recommendations $[3,4]$ resulting from this effort were that:

- Heliostats should be designed for strength (against high wind) rather than for stiffness in operational winds.

- They should be designed against standard design code wind speeds rather for the 10() - to $2(x)$-year winds.

- Because of their proximity to the receiver, 50 to $6(2 \%$ of the heliostats in a field that are closest to the receiver tower can have lower pointing accuracy and poorer beam quality without degrading heliostat field performance.

- Heliostats that are located to the inside of the heliostat field will experience a reduction of their wind loads due to shielding from the outlying heliostats and can therefore be designed to lower wind loads.

\footnotetext{
${ }^{3}$ Westinghouse participated in the design portion of this . ffort hut did not build a protolype.
} 


\begin{tabular}{|c|c|}
\hline \multicolumn{2}{|c|}{ Table 1. Second-Generation Heliostat Design Requirements [1] } \\
\hline Catcgory: & Requirements: \\
\hline Operational Modes: & $\begin{array}{l}\text { - Normal modes (track, standby, wire walk, stow) } \\
\text { - Track in up to } 35 \text {-mph wind } \\
\text { - Slew in 5()-mph wind } \\
\text { - Resolve tracking singularity in } 15 \text { minutes } \\
\text { - Reposition in } 15 \text { minutes } \\
\text { - } \text { Emergency defocus in } 3 \text { minutes } \\
\text { - } \quad \text { Electrical transients (operate through a 3-cycle dropout) }\end{array}$ \\
\hline Optical Performance: & $\begin{array}{l}\text { - Beam pointing ( } 1.5 \mathrm{mr} \text { RMS maximum, reflected heam error for } \\
\text { each axis) } \\
\text { Beam quality (theoretical beam shape plus } 1.4 \mathrm{mr} \text { fringe, } \\
32^{\circ} \mathrm{F}-122^{\circ} \mathrm{F} \text { ) } \\
\text { - Wind load deflection (3.6-mr RMS maximum reflective surface } \\
\text { deflection in } 27 \text {-mph wind, discounting foundation) } \\
\text { - Foundation deflection ( }(0.45 \text {-mr maximum set after survival), } \\
1.5 \text {-mr maximum twist or tilt in } 27 \mathrm{mph} \text { wind) }\end{array}$ \\
\hline Survival: & $\begin{array}{l}\text { - } 9(1)-m p h \text { wind, heliostat stowed } \\
\text { - } 5(1) \text {-mph wind, heliostat in any orientation } \\
\text { - Temperature, }-20)^{\circ} \mathrm{F}-122^{\circ} \mathrm{F} \\
\text { - Hail, } 3 / 4 \text { in. at } 65 \mathrm{lt} / \mathrm{sec} \text {, any orientation; } 1 \text { in. at } 75 \mathrm{lt} / \mathrm{sec}, \\
\text { heliostat stowed } \\
\text { - Cold water shock }\end{array}$ \\
\hline 3()-Year Life: & $\begin{array}{l}\text { - Life of all components must be cost effective for } 30 \text { years } \\
\text { - Mirror and drive mechanism are critical components }\end{array}$ \\
\hline
\end{tabular}

- Depending on the site of use, a narrower operational ambient temperature range may be possible and could benefit mirror modules that defocus with decreasing temperatures.

One of the more important consequences of these results was the movement in commercial heliostat design toward increased heliostat size.

\section{LARGE-AREA HELIOSTATS}

Large-area heliostats represent the continued evolution toward lower cost of the second-generation heliostats, and private industry has been responsible for that evolution. After the second-generation heliostat effort, ARCO built thirty $5.3-\mathrm{m}^{2}$ heliostats for a central receiver plant that provided process heat for enhanced oil recovery [5]. I ater, both MCDonnell Douglas and ARCO built heliostats in the $85-1095-\mathrm{m}^{2}$ size range. ARCO manufactured 865 units of this size: 864 as photovoltaic (PV) trackers and 1 as a heliostat. 756 of the PV trackers employed that mirrors to double the direct sunlight incident upon their photovoltaic modules. ARCO further increased the heliostat size to $148 \mathrm{~m}^{2}$ and built 45 such units, two of 
them as heliostats and 43 as PV trackers equipped with nearly $150 \mathrm{~m}^{2}$ of mirrors to reflect sunlight onto the PV arrays. ${ }^{4}$

In addition to increased collection area, the post-second-generation heliostats underwent several noteworthy design improvements [5]. The ARCO heliostat drive system was made simpler and less costly by the replacement of its stepper motors and their costly electronic controllers with DC motors and Hall-effect encoders. The ARCO second-generation mirror module also underwent a complete transformation. In the former design, modules were formed from mirrors mounted on a box structure substrate made of formed sheet metal ribbing. This design was replaced with laminated glass-on-glass mirrors glued to rolled-metal hat sections. The result was a lighter, less costly, and more durable mirror module. SPECO developed a 2()$\left(-\mathrm{m}^{2}\right.$ heliostat with a wind spoiler designed to reduce heliostat loads induced by high winds in the stow position. This SPECO heliostat also explored the use of second surface mirrors protected only by paint (applied to the back side).

Large-area heliostats have the potential for lower cost per unit collection area. While the cost per unit area of the mirrors and for the support structure remains fairly constant with increasing heliostat size, the cost of the remainder of the heliostat can be spread over a larger area. In other words, a heliostat field with largearea heliostats would have fewer pedestals and drive systems, and less attending controls hardware and field wiring. However, the size of a heliostat drive system and the magnitude of pedestal loads increase as the cube of the heliostat's nominal diameter. For this reason, the cost of the heliostat drive and the survival of the heliostat under dynamic wind loads are major concerns, especially large-area heliostats because of their greater mass and lower natural frequency. Another concern is the increased beam size due to nff-axis aberration and the possibility of reduced optical performance sule to gravity-induced sagging of the mirror support structure.

Given the concern over the cost and wind survival of heliostat drives, an effort to develop a low-cost drive for heliostats was started in 1986. Sandia placed a contract with Pecrless-Winsmith, Inc. to design a prototype low-cost drive [6]. The most promising design was to be built and tested in the lab and on a NSTTF heliostat. This low-cost drive replaced the drive originally supplied by ATS (manufactured by A.G. Flender), and was the ATS's drive during its test and evaluation period.

\footnotetext{
${ }^{4}$ When $A R C()$ withdrew from solar thermal R \& D, a number of $A R C O$ employees purchased the rights to ARCO's heliostat technology and formed Advanced Thermal System, Inc. (ATS). ATS supplied one of the two large-area heliostats that are the subject of this report.
} 


\section{hELIOSTAT COSTS}

Cost information for heliostat manufacture and installation in the US is limited because they have been manufactured here only in small quantities. There were 222 heliostats built and installed at the Central Receiver Test Facility (CRTF) in Albuquerque, New Mexico in 1977, and these had an installed cost of $\$ 590$ (1977\$) per square meter of energy collection area $\left(\$ / \mathrm{m}^{2}\right)$. The most manufactured were the 1,911 heliostats built for Solar I (and the Almeria solar plant) in 1980; these heliostats were built at a cost of $\$ 56() / \mathrm{m}^{2}(198() \$)$, which represents a cost reduction of about $30 \%$ over the CRTF heliostats. ${ }^{5}$ In 1983,756 mirror-enhanced PV trackers were manufactured and installed at Carrissa Plains in 1983 by ARCO; these were of mit-second-generation design. As heliostats, they would have had collection areas of $95 \mathrm{~m}^{2}$ each; their cost (estimated by adjusting the cost of the trackers for the material differences) was $\$ 214 / \mathrm{m}^{2}(1983 \$)$. Only recurring costs (and no developmental costs) were included in Fig. 2.

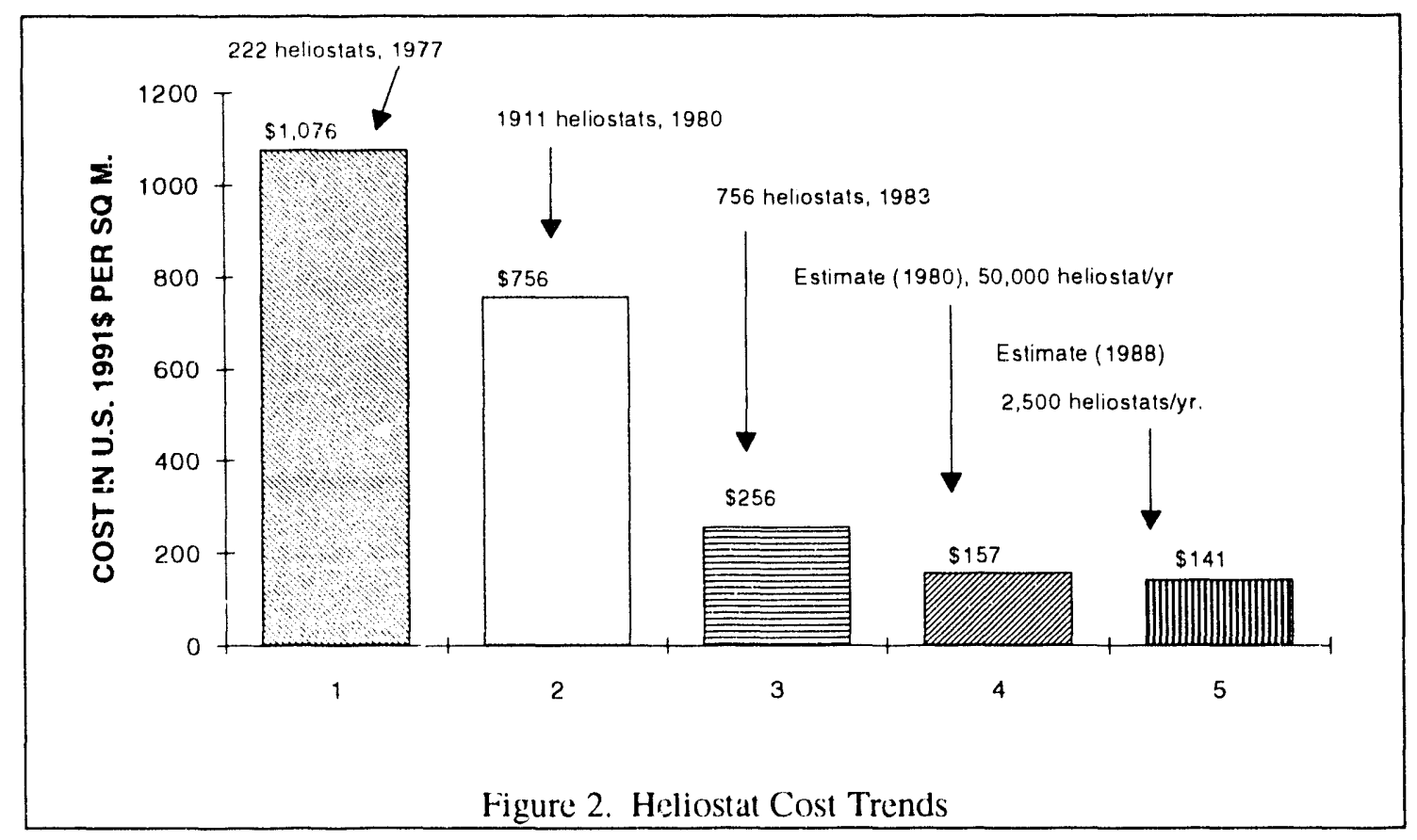

Several manufacturing studies conducted during the econd-generation heliostat development effort include cost estimates for the mass-manufacture of heliostats $[2,7]$. These studies were conducted prior to the completion of the Solar I heliostats and do not reflect the lessons learned from the manufacture of even a

\footnotetext{
5 Batsed on the Producer Price Index for durable (non-food) consumer goods, Table B-61, page 867, Economic Report to the President Transmitted wo the Congress, Februan, 1992, U.S. Government Printing Office, 1992.
} 
modest quantity of heliostats. The manufacturing cost studies undertaken by ARCO, Martin Marietta, and McDonnell Douglas as part of their second-generation development effort produced estimates that ranged from $\$ 100 / \mathrm{m}^{2}$ to $\$ 116 / \mathrm{m}^{2}$ (1980) for installed (second-generation) heliostats [7]. ${ }^{6}$ These estimates were based on assumed annual production rates of 50,000 units.

A more recent heliostat cost study provides perhaps the most accurate available estimate for large-area heliostats [8], albeit for relatively small production quantities. A study performed in 1988 for PG\&E estimated the installed cost for large-area heliostats based on the manufacture of 25,000 units over a tenyear period at a rate of 2,500 per year. Under these conditions the estimated (installed) capital cost was $\$ 131 / \mathrm{m}^{2}$ (\$1988). The results of this study are more meaningful because the study benefited from the cumulative experience in heliostat manufacture up to 1988 . However, the production rate of 2,500 heliostats per year is low, and one would expect additional cost-reductions for larger quantity heliostat manufacture.

Figure 2 provides a graphical summary of heliostat cost trends, all costs adjusted to $1991 \$$. The cost value used for the second-generation heliostat is the higher value $\left(116 \$ / \mathrm{m}^{2}\right.$ in $\left.1980 \$\right)$ cited in the Second Generation Heliostat Evaluation Executive Summary [7]. It should be notad that this estimate was made in the absence of any actual industry experience at that time in volume manufacture of heliostats. The estimate was based on an assumed production level of 50,000 heliostats per year (a rate 20 times greater than that assumed for the large-area heliostat manufacturing cost estimate made in 1988). All costs shown in the figure have been adjusted for inflation and converted into 1991 dollars using the Producer Price Index for durable, finished (nonfood) consumer goods (see footnote \#6).

\section{Objectives and Scope of the Evaluation of the Large-Area Heliostats}

In the mid-1980s, Sandia purchased two large-area heliostats with the intent of evaluating their performance characteristics. The heliostats, which had solar energy collection areas of 148 and $200 \mathrm{~m}^{2}$, were built respectively by Advanced Thermal Systems, Inc. (ATS) and Solar Power Engineering Company (SPECO). The heliostats were installed for testing and evaluation at Sandia's NSTTF, the ATS heliostat in 1986 and the SPECO in 1987.

The purpose of the test effort was to evaluate performance and durability of the devices and to seek answers to a number of related questions: would the heliostats perform according to their specifications? How much power would they be capable of delivering to a receiver? What would be the overall size of the heliostat beam? What performance penalty, if any, would there be because of the increased beam size associated

\footnotetext{
${ }^{6}$ These cost estimates were adjusted to set equal the cost of identical materials in the three studies.
} 
with a larger collector? Would the heliostats perform within specifications under moderately high winds? Would they be vulnerable to wind damage?

The results of that test and evaluation effort, which was conducted from 1987 to 1992, are presented here. The effort focused on heliostat beam quality, wind effects, heliostat drives and controls, mirror module performance and durability, and overall operational and maintenance characteristics. 


\section{DESCRIPTION OF THE LARGE-AREA HELIOSTATS}

\section{Second-Generation Heliostat Design Specifications}

As mentioned in the background discussion of Section 1, one of the important products of the DOEsponsored heliostat development effort was the definition of a set of specifications or design/performance guidelines for commercial heliostats. These specifications reflect the experience gained through two generations of heliostat design, manufacture, and testing. Known as the "Second-Generation Heliostat Design Requirements," they are reproduced [1] in Table 1 as a point of reference.

\section{The ATS Heliostat}

The riurror sections of the ATS heliostat are 1.22- $\mathrm{m}^{2}, 1-\mathrm{mm}$-thick silvered glass bonded to 3-mm glass. Its mirror modules are formed by adhering the mirrors side-by-side to four parallel, sheet-metal hat sections. The four hat sections are fastened together and stiffened by three cross members to form a mirror module.

The rectangular mirror modules are supported on the heliostat by a rack constructed from two trusses welded to the heliostat's torque tube (see Fig. 3). There are 10 mirror modules bolted to each of the heliostat's 2 racks for a total of 20 mirror modules. The torque tube itself is bolted to either side of the heliostat's elevation drive.

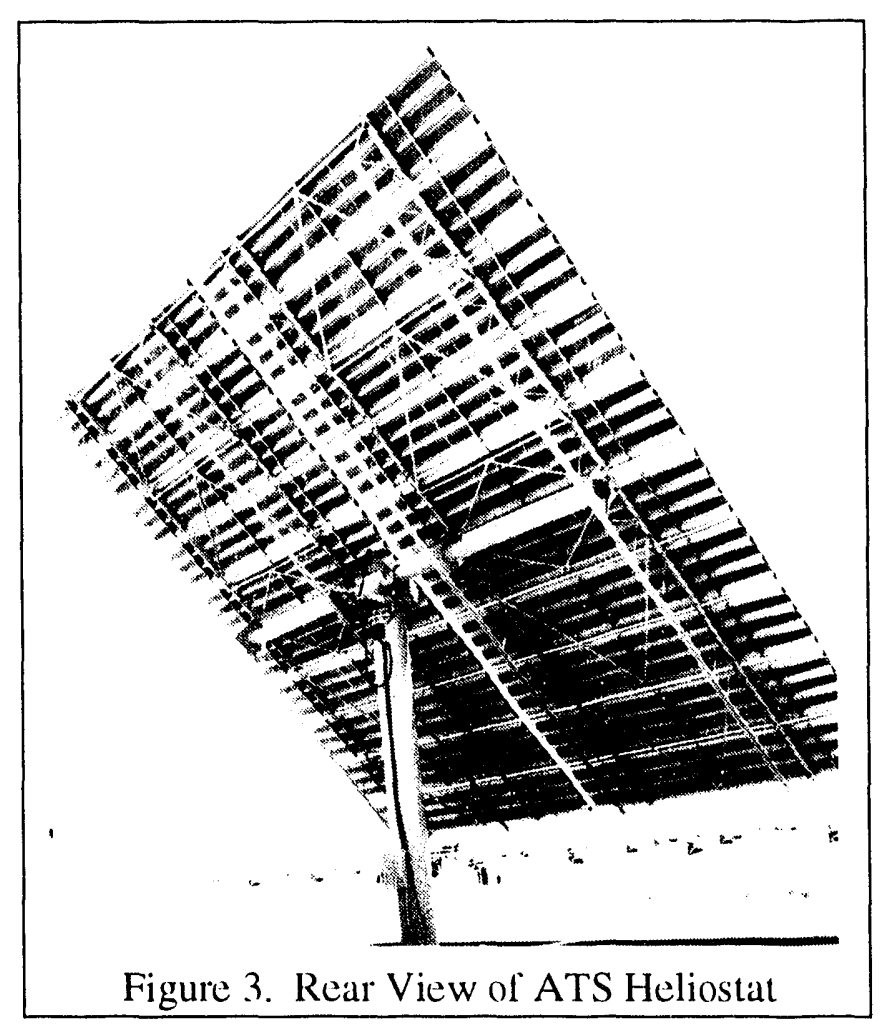

The original ATS drive system was manufactured by A.G. Flender. Its azimuth and elevation drives were both two-stage (two gears in series) worm gears with gear ratios of approximately 18,600:1. Both drives employed 90 VDC, 1/4-hp motors.

As part of the DOE effort to develop heliostat technology, a US gear manufacturer, PeerlessWinsmith, Inc. was contracted in 1986 to develop a low-cost drive for two-axis tracking solar collectors. The product of that effort [6] was installed on the ATS heliostat in 1988 so that it could be evaluated. As a result, all the tracking accuracy, wind effects, and other drive-systemrelated tests were performed on the Winsmith low-cost drive system (not the A.G. Flender drive system). Its elevation drive employs a jack 
screw, while the azimuth drive is a planocentric drive. Initially the Winsmith drive was equipped with 1/2-hp motors, but these were found to coast (had no inherent braking). This produced excessive updating by the heliostat controller and led to their replacement with 1/4-hp motors. The motors on both drives were equipped with Hall-effect encoders for position feedback.

The heliostat drive motors are controlled and driven by a local control board (mounted in a weather-tight box on the heliostat pedestal) equipped with an on-board microprocessor and power supply. Operator control of the heliostat is via a computer program running on a personal computer (PC) that is connected by its /O (inpuVoutput) port to the local control board. Manual control is also an option with a manual control box that plugs directly into the local control board at the base of the heliostat pedestal.

The essential specifications and component descriptions of the two large-area heliostats are summarized in Table 2 .

\section{The SPECO Heliostat}

The SPECO heliostat employs 3.2-mm-thick glass/mirror facets measuring $1.5 \times 1.8 \mathrm{~m}$. The glass is second surface silvered, double strength, plain float glass; the mirrored back surface is protected with a coat of white paint. Bonded to the backside of each mirror are nine threaded studs to facilitate mounting to the mirror module. The mirror modules are formed by securing two mirrors with their studs to a rectangular, hollow-tube steel frame. The 36 mirror modules are bolted to a K-frame rack structure, as shown in Fig. 4 with four rows and nine modules per row.

The K-frame rack to which all the mirror modules are secured is bolted to the elevation gear housing. The elevation drive gear in turn is mounted atop the azimuth gear box, which itself is affixed to the heliostat's ().61 m (2 ft) diameter steel pedestal.

The SPECO heliostat has two wind spoilers perpendicular to the mirrored surfaces and attached to the top and bottom edges of the heliostat (visible in Fig. 4).

The SPECO's azimuth and elevation drives are worm gears (with 29,200:1 ratios). They are actuated by 1/4-hp DC motors with Hall-effect encoders for position feedback. The drive was manufactured by Hub City.

The designers of the SPECO heliostat opted to use the same heliostat control system developed by ATS and employed in their heliostat. It is described in the preceding section. 


\begin{tabular}{|c|c|c|}
\hline & SPECO & ATS \\
\hline Configuration: & Glass-Metal Dual Axis Tracking & Glass-Metal Dual Axis Tracking \\
\hline $\begin{array}{l}\text { Area: } \\
\text { Height } \\
\text { Width }\end{array}$ & $\begin{array}{ll}200.3 \mathrm{~m}^{2} & \left(2,156 \mathrm{ft}^{2}\right) \\
14.75 \mathrm{~m} & (48.39 \mathrm{ft}) \\
14.52 \mathrm{~m} & (47.64 \mathrm{ft})\end{array}$ & $\begin{array}{l}146.9 \mathrm{~m}^{2}\left(1,581 \mathrm{ft}^{2}\right) \\
12.56 \mathrm{~m}(41.21 \mathrm{ft}) \\
12.34 \mathrm{~m}(40.49 \mathrm{ft})\end{array}$ \\
\hline Stow Position: & $\begin{array}{l}\text { Normal: vertical } \\
\text { High wind: horizontal, face up }\end{array}$ & $\begin{array}{l}\text { Normal: vertical } \\
\text { High wind: horizontal, face up }\end{array}$ \\
\hline $\begin{array}{l}\text { Mirror Modules: } \\
\text { Size } \\
\text { Area } \\
\text { Height } \\
\text { Width } \\
\text { Reflectivity } \\
\text { Mirror } \\
\text { Backing \& } \\
\text { Substrate: }\end{array}$ & $\begin{array}{l}-\quad 5.57 \mathrm{~m}^{2}\left(60 \mathrm{fi}^{2}\right) \\
-\quad 5.52 \mathrm{~m}(5.00 \mathrm{ft}) \\
\quad 3.66 \mathrm{~m}(12.01 \mathrm{ft}) \\
\text { - } \quad 83 \% \\
\text { 3.2-mm silvered glass ( } 1.5 \mathrm{~m} \times 1.8 \mathrm{~m} \\
\text { facet); its mirrored backside is } \\
\text { protected with paint. } \\
9 \text { threaded studs attached to backside } \\
\text { of facet. } 2 \text { facets per module. } \\
\text { The stecl frame module is bolted at } 3 \\
\text { locations to a "K-frame" rack } \\
\text { structure designed with integral } \\
\text { wind spoilers. }\end{array}$ & $\begin{array}{l}\text { - } \quad 7.44 \mathrm{~m}^{2}\left(80 \mathrm{ft}^{2}\right) \\
-\quad 6.22 \mathrm{~m}(4.00 \mathrm{ft}) \\
\text { - } \quad 94 \% \\
\text { 1-mm silvered glass bonded to } \\
\text { 3-mm glass. Module formed by } \\
\text { bonding } 5 \text { mirrors to an aluminized } \\
\text { sheet metal hat section with cross } \\
\text { members attached by } 4 \text { threaded studs. } \\
\text { These are positioned at four points to } 2 \\
\text { truss racks which are welded to a } \\
\text { torque tube. The tube is bolted to both } \\
\text { sides of the elevation drive. }\end{array}$ \\
\hline $\begin{array}{l}\text { Drive System: } \\
\text { Azimuth } \\
\text { Elevation } \\
\text { Motors } \\
\text { Electronics }\end{array}$ & $\begin{array}{l}\text { Dual axis drive }{ }^{8} \text { mounted at top of } \\
\text { pedestal } \\
\text { - } 29,200: 1 \text { ratio worm gear } \\
\text { - } 29,200: 1 \text { ratio worm gear } \\
\text { 1/4-hp DC, with Hall-effect } \\
\text { position indicators } \\
\text { - Heliostat controller via } \\
\text { microprocessor and power supply. } \\
\text { Computer with I/O heliostat } \\
\text { controller. }\end{array}$ & $\begin{array}{l}\text { Low-cost heliostat drive mounted to } \\
\text { top of pedestal } \\
\text { Planocentric drive } \\
\text { Jack screw } \\
\text { 1/4-hp DC, with Hall-effect } \\
\text { position indicators. } \\
\text { IIeliostat controller via } \\
\text { microprocessor and power } \\
\text { supply. } \\
\text { Computer with I/O heliostat } \\
\text { controller. }\end{array}$ \\
\hline Pedestal: & $\begin{array}{l}0.61-\mathrm{m}-(2 \mathrm{ft}) \text { diameter steel pipe } \\
\text { pedestal placed in augured hole with } \\
\text { concrete backlill. }\end{array}$ & $\begin{array}{l}0.61-\mathrm{m}-(2 \mathrm{ft}) \text { diameter steel pipe } \\
\text { pedestal placed in augured hole with } \\
\text { concrete backfill. }\end{array}$ \\
\hline
\end{tabular}

\section{Mirror Focal Length and Heliostat Canting Range}

The focal length of the individual mirrors in a module is set during their manufacture by giving them a slight curvature. The ATS mirror modules were manufactured with a nominal focal length of $305 \mathrm{~m}(1000 \mathrm{fi})$. The SPECO mirror modules were manufactured with a nominal focal length of $244 \mathrm{~m}(8()) \mathrm{ft}$ ).

\footnotetext{
${ }^{7}$ Solar-averaged hemispherical reflectivity of clean mirror following installation of the heliostat.

${ }^{8}$ Manufactured by Ilub City.
} 
When mounted to the module support structure, the individual mirror modules were aimed (or canted) to a common aim point corresponding to the slant range of the heliostat (to the intended receiver). The design slant range for the ATS and SPECO was $235 \mathrm{~m}(771 \mathrm{ft})$.

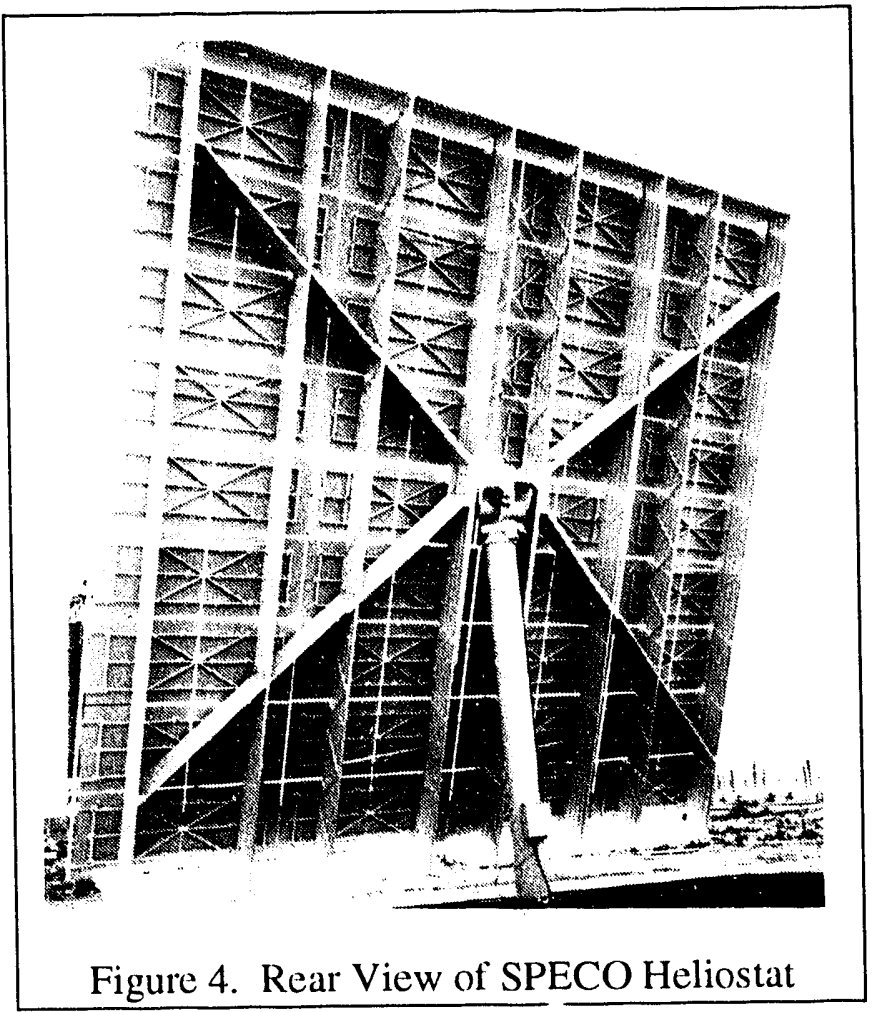




\section{TESTING AND EVALUATION OF THE LARGE-AREA HELIOSTATS}

\section{Overview}

The ATS heliostat was installed at Sandia's NSTTF in Albuquerque, New Mexico, in 1986; the SPECO in 1987. The test program covered the six-year period from 1986 through 1992, and focused on the issues of heliostat beam quality, mirror module performance and durability, tracking accuracy, dynamic wind effects, and overall operational and maintenance characteristics. A number of evaluation tools was employed in this effort, the most important of which are described here.

\section{Tools}

\section{THE BEAM CHARACTERIZATION SYSTEM}

The Beam Characterization System [9] (BCS) is a primary tool used at the NSTTF for evaluating the performance characteristics of solar concentrators and their mirror modules or facets. It was used in numerous tests of the large-area heliostats including beam quality, dynamic wind effects, and tracking accuracy and repeatability tests.

In tests such as these, the BCS is employed to image the beam of concentrated solar energy as it is tracked by the heliostat on a flux target. The result of the BCS process is a flux map of that beam. The information obtained includes 1) the location of the beam centroid and peak, 2) the flux densities over the entire beam, 3) the peak flux ,4) the total beam power, and 5) the nominal diameter of a circle that contains all flux equal to or greater than $10 \%$ (or any specified percentage) of the peak flux. Other standard image analysis functions can also be performed on the BCS image.

The components of the BCS system and their interrelation are depicted in Fig. 5. The flux target used by the BCS is a white, nonspecular reflective surface with unique optical properties. The relative position of the target approximates the position of a solar receiver in a central receiver plant. (Because of practical considerations, it is actually positioned somewhat lower than a receiver would be, approximately at the midpoint of Sandia's solar tower.) Images of the heliostat beam on the target are captured using a video-type camera positioned at a convenient location with a normal or near-normal view of the target. The target surface is painted with a high-temperature titanium-oxide paint. Because of the diffuse (Lambertian) reflectance characteristics of the target, the intensity of the reflected light reaching the camera from each point on the surface of the target is directly (linearly) proportional to the intensity of the light reaching that same point on the target from the concentrator. This characteristic of the BCS target is essential to the measurement technicue and ensures the desired result: the image of the flux beam captured by the camera is a scaled version of the actual flux incident upon the target. 


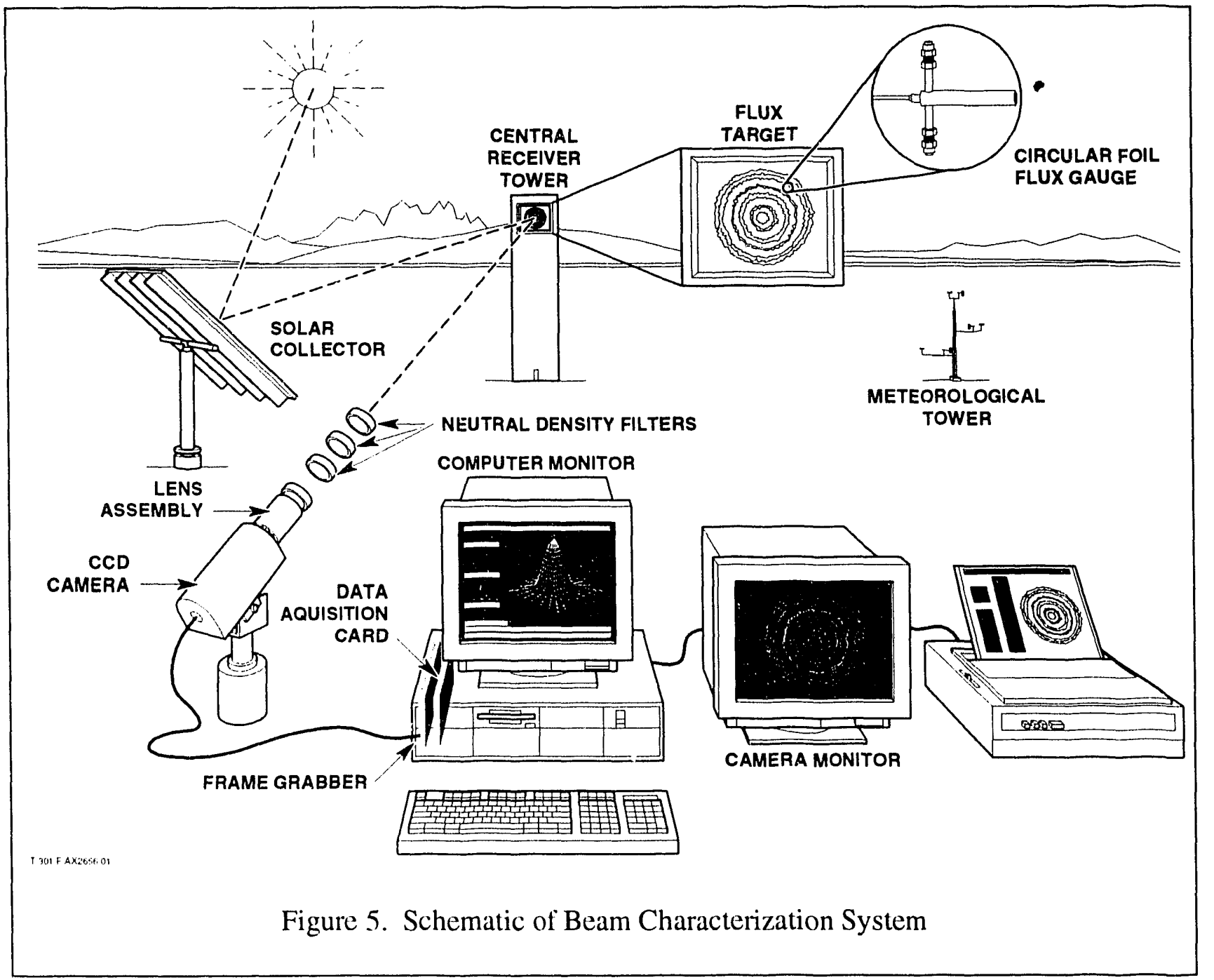

Because of the extreme brightness of the light from the target, the BCS camera is equipped with neutral density filters to attenuate the light to within the camera's working dynamic range. The lens system may or may not include a zoom lens, depending on the distance from the camera to the BCS target. In any case, the target and the collector beam are imaged on the camera's sensor, digitized by a commercial frame-grabber, and processed by image analysis software that is resident on the BCS's high-end personal computer.

A flux gauge mounted on the surface of the BCS target provides a single absolute measurement of flux at one point in the BCS image. Together with the value of the picture element (pixel) intensity at that location in the image, the flux gauge reading is used to establish a conversion factor, which can be applied to the BCS image. Using this factor, the intensity value of every pixel in the image is converted into an absolute flux density value. In this manner the BCS image becomes a flux map. 
The analysis functions of the commercial image analysis system (IAS) produce most of the required BCS information, including the locations of the beam centroid and peak flux, and the diameter of the beam. ${ }^{9}$ When multiple images are analyzed, such as in tracking error or dynamic wind effect tests, the IAS can compute and display the movement of the beam centroid from image to image.

As stated before, the magnitude of the peak power and the total beam power is obtained by applying the conversion factor (pixel-level-to-flux-density) to the IAS's results (which are in relativistic, pixel-intensity units).

The BCS also has analog data acquisition capability, which is employed to measure the flux gauge mentioned above and relevant environmental conditions including wind speed, wind direction, and normal incident insolation. These instrument readings are acquired at the same time as the beam image data. Meteorological data acquisition is described below.

The results from the analysis of image and non-image data are typically transferred to a spreadsheet for final analysis. Based on a preliminary error analysis of the BCS, the expected measurement error (i.e., the standard deviation for measurements) of that system for the tests described in this report is 6 to $10 \%$. Measurement resolution is approximately $1 \%$ of the full-scale flux value measured. An analysis of the BCS error sources is provided in Appendix D.

\section{METEOROLOGICAL DATA}

Environmental conditions including wind speed, wind direction, and direct normal solar insolation can be measured each time a BCS image is acquired. A meteorological tower located 10() $\mathrm{m}$ west of the ATS heliostat ${ }^{10}$ is equipped with wind speed (3-cup anemometers) and wind direction (lightweight vanes) sensors at three heights: 10.0, 6.1, and $3.1 \mathrm{~m}(32,20$, and 10 (i) above the ground. A normal incidence pyroheliometer (NIP) is mounted on a separate platform located $75 \mathrm{~m}$ north of the two large-area heliostats. Cabling from these sensors as well as from the flux gauge is routed to a data acquisition board in the PC, which is the platform for the BCS. Each time a camera image is acquired, the BCS is able to sample each of the sensors and digitize the reading; the meteorological data is then stored with or separate from the acquired beam image, as desired.

\footnotetext{
9Typically, the diameter of a circle containing all flux that is greater or equal to $10 \%$ of the peak flux.

${ }_{10}$ The SPICCO is located $50 \mathrm{~m}$ due east of the ATS: the two heliostats are both $240 \mathrm{~m}$ north of the NSTTF's Solar Tower upon which is located the BCS targel at a height of about $30 \mathrm{~m}$.
} 


\section{REFLECTIVITY MEASUREMENTS}

Mirror reflectivity was measured (both clean and dirty) at regular intervals throughout the six-year test period. The specular reflectivity of the mirrors was measured with a Device and Services (D \& S) Portable Specular Reflectometer Model 15R (Serial \#()13), using a receiver aperture set to an effective acceptance angle of $15 \mathrm{mr}$. This instrument has an accuracy of 0.01 , a repeatability of 0.005 , and a resolution of 0.001 , all in absolute reflectance units [10]. Because the D \& S device uses 660-nm-wavelength light as its light source, the measured reflectance values require an adjustment to obtain a solar average specular reflectivity value for the heliostat. Information regarding this procedure is provided in Appendix $\mathrm{E}$.

\section{Mirror Module Evaluation}

\section{MIRROR REFLECTIVITY}

The ATS and the SPECO mirrors employ silver mirroring material (mirror module design and composition described in Section 2). The mirrors (mployed for the SPECO heliostat were known in advance to have low reflectivity, but Sandia accepted their use as an expedient. This type of mirror, however, would normally not be selected for a working (commercial) collector system.

During the evaluation period at Sandia, the heliostats were not cleaned except by the natural effect of rain and snowfall. Exceptions to this were made on two or three occasions when, for the purpose of investigating cleaning techniques, the mirror modules were sprayed with a high-pressure solution of water and cleaning agent. Reflectivity measurements were made of the clean and of the dirty or "as is" condition of the mirrors. The clean mirror measurements were made after wetting a portion of a mirror modules with deionized water and then wiping dry that area with an absorptive paper towel. Each (clean or dirty) specular reflectance value was obtained from 20 measurements at randomly selected points on the mirror modules on the bottom row of the heliostat (the row closest to the ground when the heliostat is in the vertical position). The average of the 20 measurements was then computed and adjusted to obtain the solar average value.

\section{Long-Term Mirror Degradation}

The reflectivity of the mirror modules of the two heliostats suffered an average degradation rate of 0.6 to ().7\% per year during the evaluation period. These trends in clean mirror reflectivity are plotted in Fig. 6 . The trend in degradation is fairly linear: there is no indication from the data of a leveling off of the degradation. 


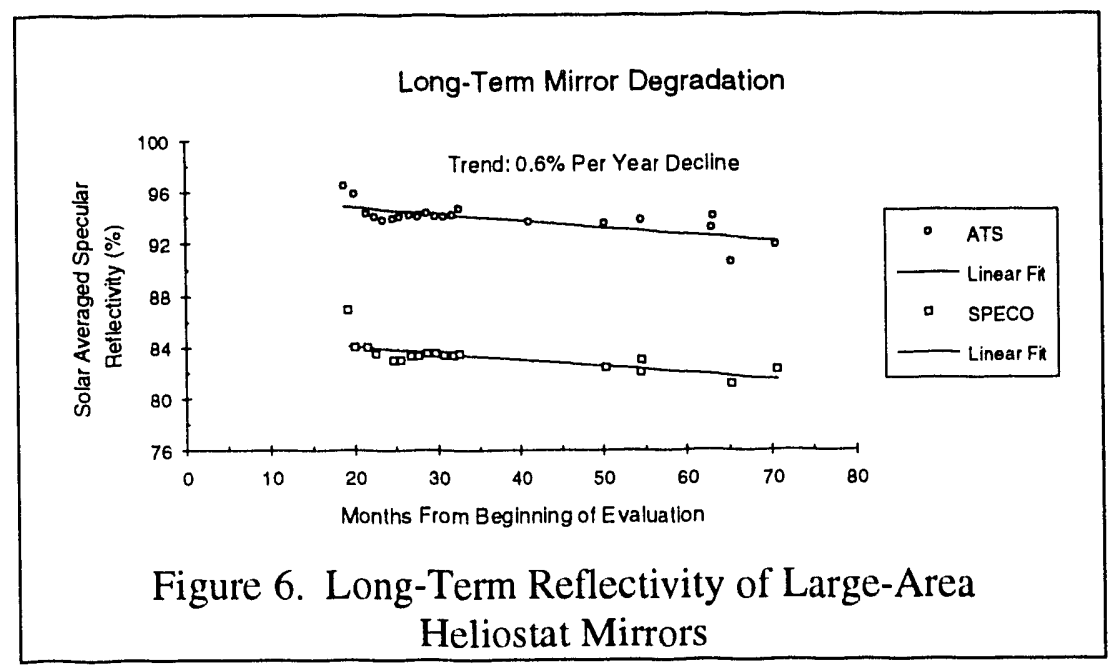

\section{Mirror Soiling}

The "as is" reflectivity of the mirror modules of both heliostats varied considerably over the short term, due to soiling by the interaction of airborne soil, water condensation on mirrors, and rain and snow. To demonstrate the effect of mirror soiling, the "as is" (dirty) mirror reflectivity of the ATS heliostat is plotted in Fig. 7 as a percentage of the current clean-mirror reflectivity value. The SPECO heliostat data exhibited a very similar trend. Note that on this plot a reflectivity value of $100 \%$ only indicates that the dirty and clean mirror reflectivity was the same at that time (probably due to the cleaning action of a recent rain or snowfall). This plot illustrates the magnitude of the negative effect soiling will have on heliostat field power production. On the average, soiling reduced mirror reflectivity (and therefore thermal power output) of the large-area heliostats by 6.3 and $8.8 \%$ for the ATS and the SPECO, respectively.

\section{MIRROR MODULE DURABILITY}

\section{Mirror Corrosion}

A detailed inspection of the mirror modules of both heliostats was performed in August 1992 to determine the condition of both mirrors and modules. Several mirrors on the SPECO heliostat were broken by snow accumulation caused by interference of the lower wind spoiler with the bottom row of mirrors. (More details are provided in "Mirror Breakage and SPECO Wind Spoiler Design"). Excepting that, the condition of the SPECO mirrors and the mirr.sr modules was good. A minor amount of flaking of the protective paint on the rear edges of some of the mirrors was observed, however. (The SPECO mirrors are 3.2-mm backsurface silvered mirrors with a protective coat of white paint.) The nominal dimensions of the dried flakes of protective paint observed along the mirror edges were approximately $1 / 3 \times 1 / 3 \mathrm{in}$. Slight corrosion of the silver mirroring material was observed at the sites where peeling had occurred. There was no indication that 


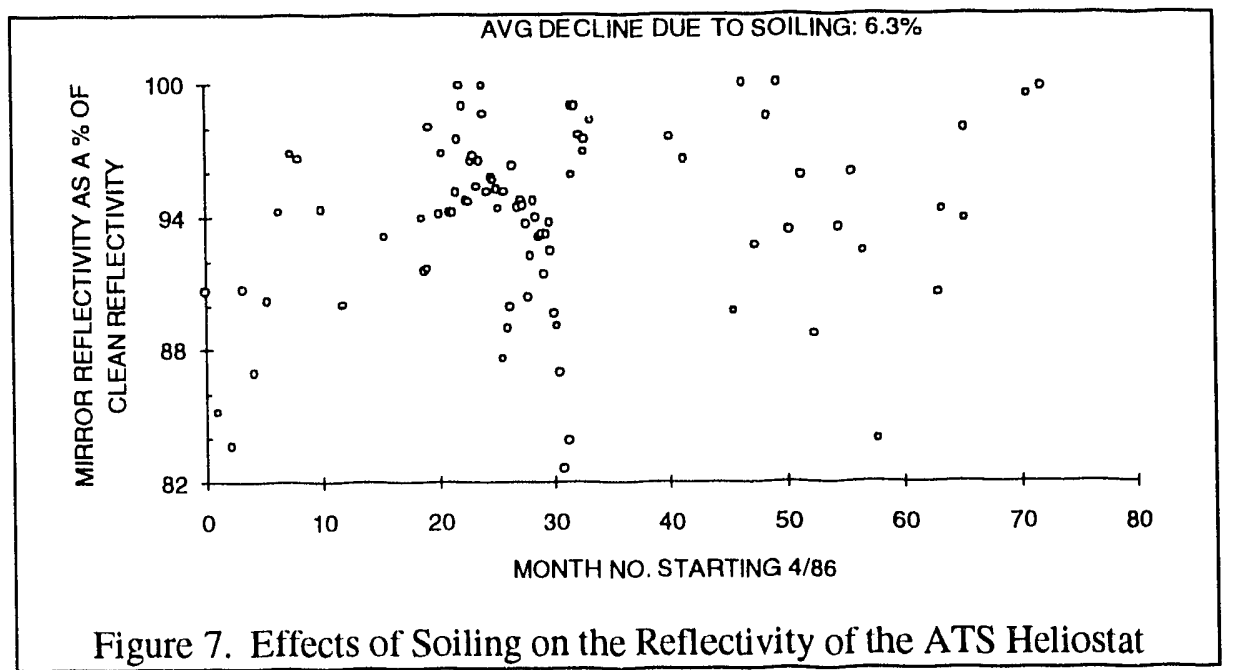

the peeling process was advancing inward to the interior surface areas of the mirrors. This peeling, and the associated mirror corrosion, was observed on 6 of the 24 SPECO mirrors that were inspected.

SPECO mirror modules, the immediate support structure for the mirrors, were also in good condition. The pads to which the threaded studs are attached and which are bonded to the back surface of the mirrors showed no evidence of debonding or deterioration of their adhesive.

The ATS mirrors and modules were also found to be in good condition, with no evidence of corrosion or debonding of any kind. Some broken mirrors were observed; the breaking occurred at the time of failure of the (Winsmith) low-cost heliostat drive. (More details are provided in "Failure and Modification of the Low-Cost Heliostat Drive".) There was some indication of slight mirror corrosion along some of the broken edges of these mirrors.

\section{Mirror Breakage and SPECO Wind Spoiler Design}

Breakage of several SPECO mirrors took place during the winter of 1990. Snow had accumulated on the mirror modules while the heliostat was in its stowed horizontal position. ${ }^{11}$ To remove the snow, the heliostat was moved to a vertical position so the snow could slide off the mirror modules. When the snow slid off the mirror modules it landed on the lower wind spoiler where it became packed and trapped. When the heliostat was returned to the heliostat stow position, the weight of the accumulated packed snow was sufficient to break the lower edges of two of the eight mirrors on the bottom row.

${ }^{11}$ The horizontal stow position is favored because it is the position of least vulnerability during high winds. 
There was no indication from the evaluation that the SPECO mirrors were substandard. Rather, the lesson learned was that this particular arrangement of the lower wind-spoiler facilitates the accumulation of ice or snow on mirrors and can result in breakage. A redesign of the lower wind spoiler is suggested, as well as attention to any structural elements at the boundaries of the mirror modules. The experience also suggests that snow removal should be a well-planned maintenance activity in systems that have large solar collection areas.

\section{Beam Characterization}

\section{BEAM QUALITY}

\section{Purpose of Beam Quality Testing}

The optical performance of the large-area heliostats was measured in order to characterize the concentrated solar energy they can deliver to the eentral receiver. The objectives of the beam quality tests included a) characterization of the heliostat beam, including total beam power, peak power, and overall beam shape and b) evaluation of changes in beam quality throughout the day (due to gravity effects as the heliostat elevation angle varied, changes in insolation and sunshape, and changes in heliostat-10-receiver orientation.

\section{Description of the Beam Quality Test}

The primary tool used for beam quality tests was the BCS. The BCS is described in some detail in the subsection "Tools" in the introduction to this section.

For the beam quality tests, an image of the heliostat beam was captured with the BCS as he beam was tracked on a flux target. The image was then scaled into flux density units by applying to each pixel in the digitized image a (pixel-intensity-to-flux-density) conversion factor, based on the measure of a single flux gauge in the BCS target. The processed image reveals the peak power density, the locations of the peak as well as the beam eentroid, the total power, the cross-sectional area containing the power, and the overall distribution of the power in the heliostat beam.

On several representative days of the year, beam quality measurements of the two large-area heliostats were made with the BCS over the course of the day. These lests were performed under clear-sky and low wind speed conditions (less than 1 () mph).

The results of the beam quality test are a gend measure of the flux distribution that these heliostats can deliver to a central receiver. (iiven that the thux measurements are made on the BCS target, the specific spatial relationship of the heliostats to the BCS target was as follows: 
- the slant range from both heliostats to the BCS target was $240 \mathrm{~m}(8(0) \mathrm{ft})$.

- the elevation angle from the heliostats to tie targ't was $5^{\circ}$.

- the target was south of both heliostats to within $5^{\circ}$.

\section{Results of the Beam Quality' Test}

The all-day beam quality tests that were performed on the ATS and SPECO heliostats included tests performed on August 26 and 27, 1991, respectively. The results on these two days are presented because they are typical as well as representative of all test results obiained. On both test days, the beam quality measurenients were made at 3()- to 45-minute intervals over the course of the day using the BCS. Each heam quality measurement produced an estimate of the heliostats' total beam power (in $\mathrm{kW}$ ), the peak flux $\left(\mathrm{kW} / \mathrm{m}^{2}\right)$, and the beam diameter $(\mathrm{m})$. The direct normal insolation $\left(\mathrm{kW} / \mathrm{m}^{2}\right)$ and the wind speed and direction were also measured at each of these times. For each test, an estimate was made as to the theoretical maximum total beam power, based on the measured insolation, the total reflective area of the heliostat, its reflectivity (as measured at the time of the test), and the angle between the heliostat normal and the sun (to calculate the resulting cosine loss) at the time of the measurement. Given the measurement uncertainty inherent in the BCS, the total power and peak flux values reported here have an expected measurement uncertainty (sta.sdard deviation) of 6 to $10 \%$. Significant differences occurred betw - n the measured and the calculated total heam power for the heliostats (particularly the ATS measurements), but they are within the expected ( $1(1 \%)$ error range. An error analysis of the BCS is presented in Aprendix D.

\section{ATS Heliostat Beam Quaitty Measuremonts}

The all-day beam quality test of the ATS consisted of 20) B(SS measurements made at 3()- to 45-minute intervals throughout the day. Contour plots for a selection of nine of these measurements are provided in Fig. 8. The effects of cosine angle and insolation kevel on the heam shape are easily appreciated from the plots: at times distant fre; iolar noon, the reduced insolation and the larger cosine loss result in reduced power and a larger heam diameter.

Table 3 provides a listing of 1 : actual measured values for total beam power, peak flux, and bean diameler associated with the nine contour plots. 


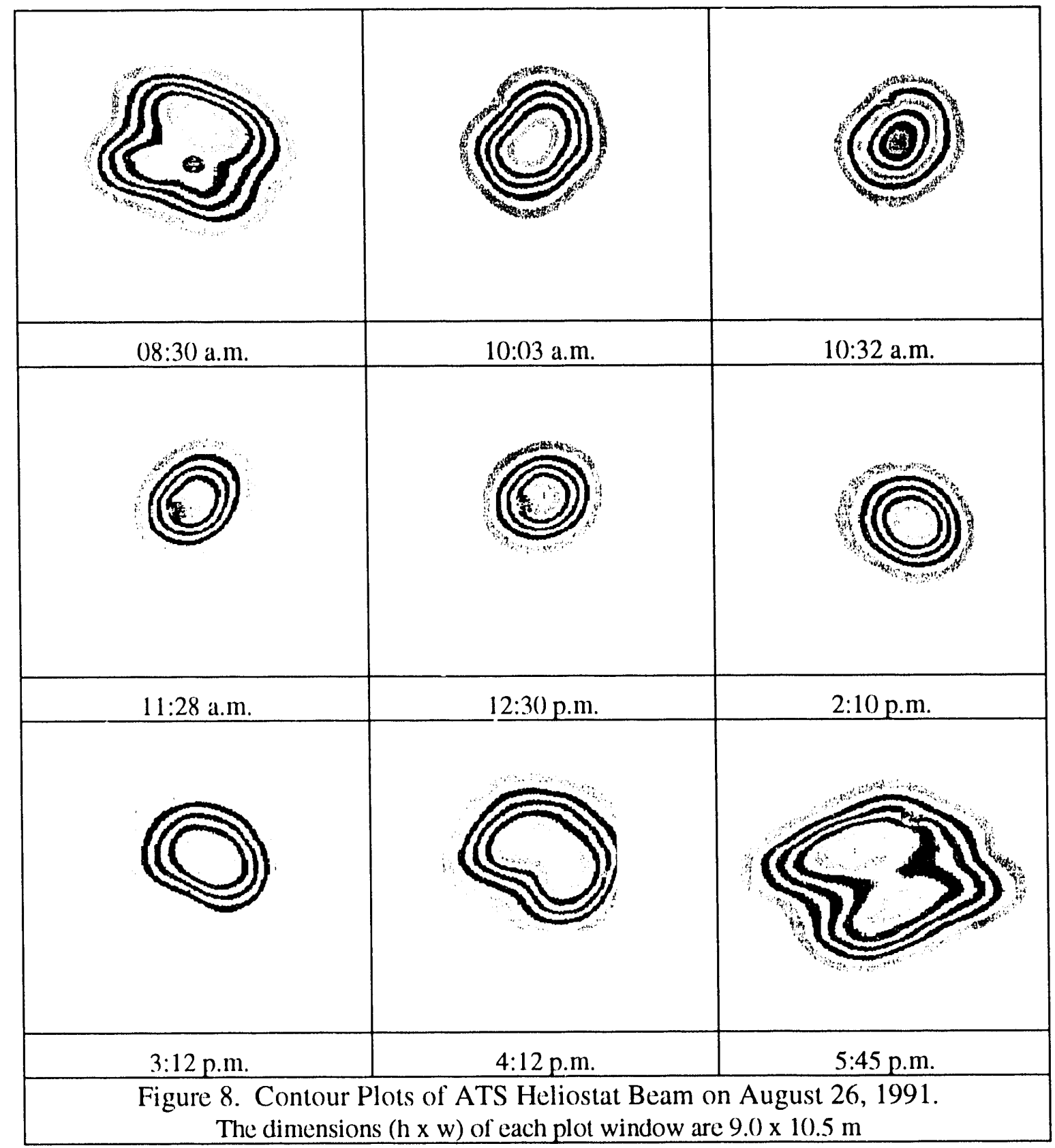

It is evident from the contour plots that outside 3 hours from solar noon the ATS beam size begins to increase significantly, and at 4.5 hours or more from solar noon the beam begins to take on a bimodal distribution, an evident divergence of the solar energy reflected from the left and right halves of the collector. This may be caused by gravity-induced deflection of the left and right sides of the mirror module support structure relative to one another. (See section titled "Comments on Off-Noon Performance and Modeling.")

The measured values for beam power, peak flux, beam diameter, etc. for all 20) BCS measurements (of August 26) are plotted in Fig. 9. A table containing those data values is provided in Appendix B. 


\begin{tabular}{|c|c|c|c|c|c|}
\hline & Hours from & Insolation & Beam & Peak & Beam \\
\hline \multirow[t]{2}{*}{ Time } & Solar Noon & $\left(\mathrm{kW} / \mathrm{m}^{2}\right)$ & Power & Flux & Diameter $(\mathrm{m})$ \\
\hline & & & $(\mathrm{kW})$ & $\left(\mathrm{kW} / \mathrm{m}^{2}\right)$ & \\
\hline $08: 30$ & -4.63 & 0.72 & 71 & 4.59 & 6.22 \\
\hline $10: 03$ & -3.08 & 0.85 & 92 & 10.60 & 4.84 \\
\hline $10: 32$ & -2.60 & 0.88 & 101 & 13.87 & 4.49 \\
\hline $11: 28$ & -1.67 & 0.91 & 101 & 18.49 & 3.99 \\
\hline $12: 30$ & -0.63 & 0.94 & 111 & 21.02 & 3.89 \\
\hline $14: 10$ & 1.03 & 0.93 & 106 & 16.81 & 4.30 \\
\hline $15: 12$ & 2.07 & 0.91 & 99 & 11.36 & 4.93 \\
\hline $16: 12$ & 3.07 & 0.87 & 94 & 7.25 & 5.69 \\
\hline $17: 45$ & 4.62 & 0.72 & 67 & 3.24 & 7.21 \\
\hline
\end{tabular}

When normalized to a one-sun level (defined as an insolation level of $1 \mathrm{~kW} / \mathrm{m}^{2}$ ) the maximum total power observed for the ATS on that date was $119 \mathrm{~kW}$. The highest peak flux level observed was $21.0 \mathrm{~kW} / \mathrm{m}^{2}$, and the smallest beam diameter was $3.9 \mathrm{~m}$.

\section{SPECO Heliostat Beam Quality Measurements}

The contour plots of selected images of the SPECO heliostat beam shown in Fig. 10) reveal the changing shape of the beam over the course of the day. The increase in beam size at times away from solar noon is more pronounced for the SPECO than for the ATS. This is due only in part to the larger size $\left(200 \mathrm{~m}^{2}\right)$ of the SPECO. Table 4 lists the actual measured parameters (beam power, peak flux, etc.) corresponding to each of the contour plots.

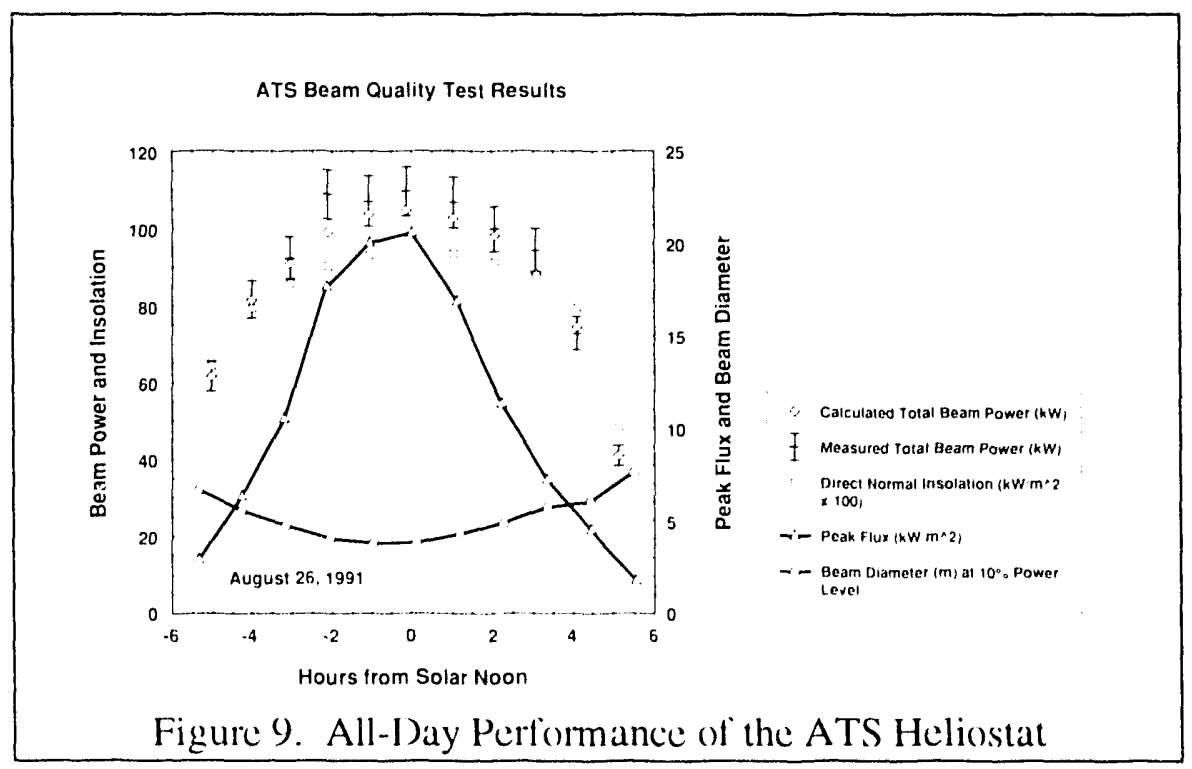




\begin{tabular}{|c|c|}
\hline & \\
\hline &
\end{tabular}

The increase in the beam diameter and its splitting in half is quite substantial at time distant from solar noon, and may be an indication of deflection of the SPECO's mirror module support structure (see discussion in the "Comments on Off-Noon Performance and Modeling").

The SPECO's performance over the entire test day is depicted in a multiple-overlay plot in Fig. 11, while the corresponding data values are tabled in Appendix A.

The normalized noontime total beam power of the SPECO was measured at $129 \mathrm{~kW}$, and the highest peak llux (actual, not normalized) was $16.7 \mathrm{~kW} / \mathrm{m}^{2}$. The smallest observed beam diameter was $4.7 \mathrm{~m}$. 


\begin{tabular}{|c|c|c|c|c|c|}
\hline \multicolumn{6}{|c|}{ Table 4. Measured Beam Characteristics of SPECO } \\
\hline & $\begin{array}{c}\text { Time } \\
\text { Time }\end{array}$ & $\begin{array}{c}\text { NIP } \\
\text { from SN }\end{array}$ & $\begin{array}{c}\text { Beam } / \mathrm{m}) \\
\text { Power }(\mathrm{kW})\end{array}$ & $\begin{array}{c}\text { Peak } \\
\text { Flux } \\
\left(\mathrm{kW} / \mathrm{m}^{2}\right)\end{array}$ & $\begin{array}{c}\text { Beam } \\
\text { Diameter } \\
(\mathrm{m})\end{array}$ \\
\hline $8: 30$ & -4.63 & 0.748 & 76.9 & 2.54 & 9.18 \\
\hline $10: 01$ & -3.12 & 0.888 & 102.2 & 4.60 & 7.72 \\
\hline $11: 03$ & -2.08 & 0.929 & 111.2 & 8.14 & 6.35 \\
\hline $12: 04$ & -1.07 & 0.941 & 115.9 & 12.52 & 5.22 \\
\hline $13: 00$ & -0.13 & 0.945 & 119.9 & 15.92 & 4.75 \\
\hline $14: 00$ & 0.87 & 0.946 & 116.3 & 15.03 & 4.86 \\
\hline $15: 00$ & 1.87 & 0.912 & 112.3 & 9.91 & 5.90 \\
\hline $16: 30$ & 3.37 & 0.894 & 105.9 & 5.25 & 7.61 \\
\hline $18: 00$ & 4.87 & 0.736 & 75.2 & 2.79 & 8.56 \\
\hline
\end{tabular}

\section{Comparing the Beam Quality of the Two Heliostats}

In order to compare the optical performance of the two heliostats, the test data was normalized in a manner intended to eliminate differences due to collector areas, insolation, and collector-to-sun-to-target geometry. The resulting performance data of the two heliostats is plotted together in Figs. 12 and 13. In the plots, the beam power test data has been normalized a) to $1 \mathrm{~m}^{2}$ of heliostat reflective area, b) to an average insolation level for the time of each measurement, and c) to an average cosine loss (i.e., to an average collector-to-sun-

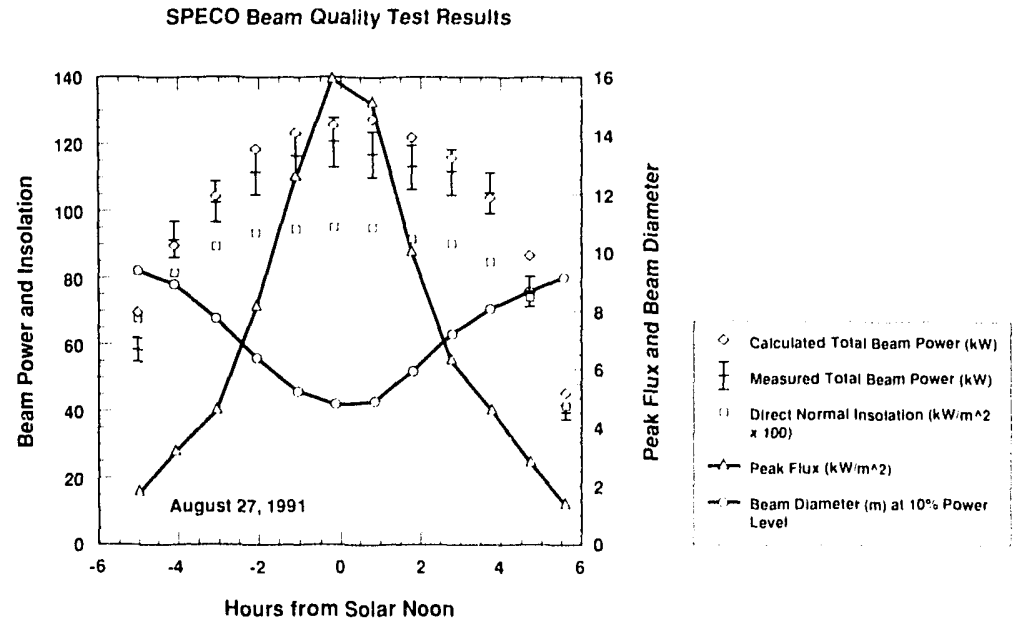

Figure 11. All-Day Pcrformance of the SPECO Heliostat 


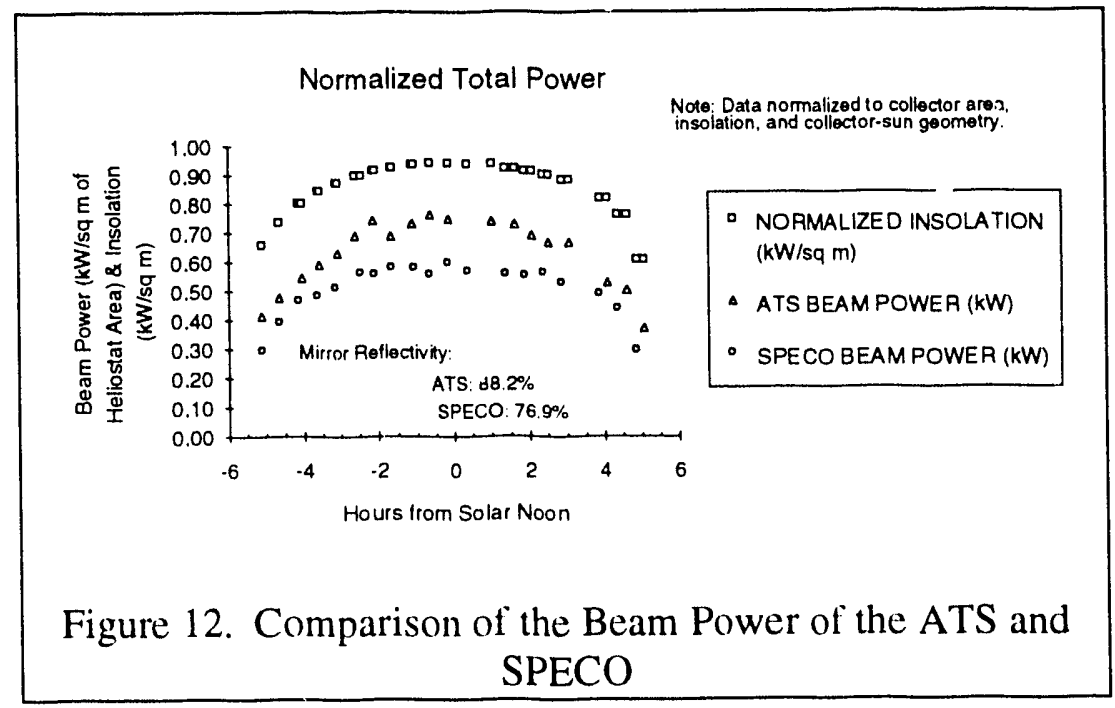

to-BCS target geometry) for the time of each measurement. The direct normal irsolation (NIP) values are the time-local average of NIP measurements made on the days of the ATS and SPECO beam quality tests. The measured peak flux values were normalized in terms of those average insolation values. Finally, the beam diameter values have been plotted unchanged.

A precise statement of the normalization or treatment of the data shown in these plots is provided in Appendix E.

The intent of the normalization process was to preserve the verisimilitude of the data by retaining the effect on power collection of the reduced insolation. the higher air mass, and the poorer sun-heliostat-target geometry in the carly morning and late afternoon while eliminating the effects of different heliostat collection areas, insolation levels, and heliostat-to-sun orientations.

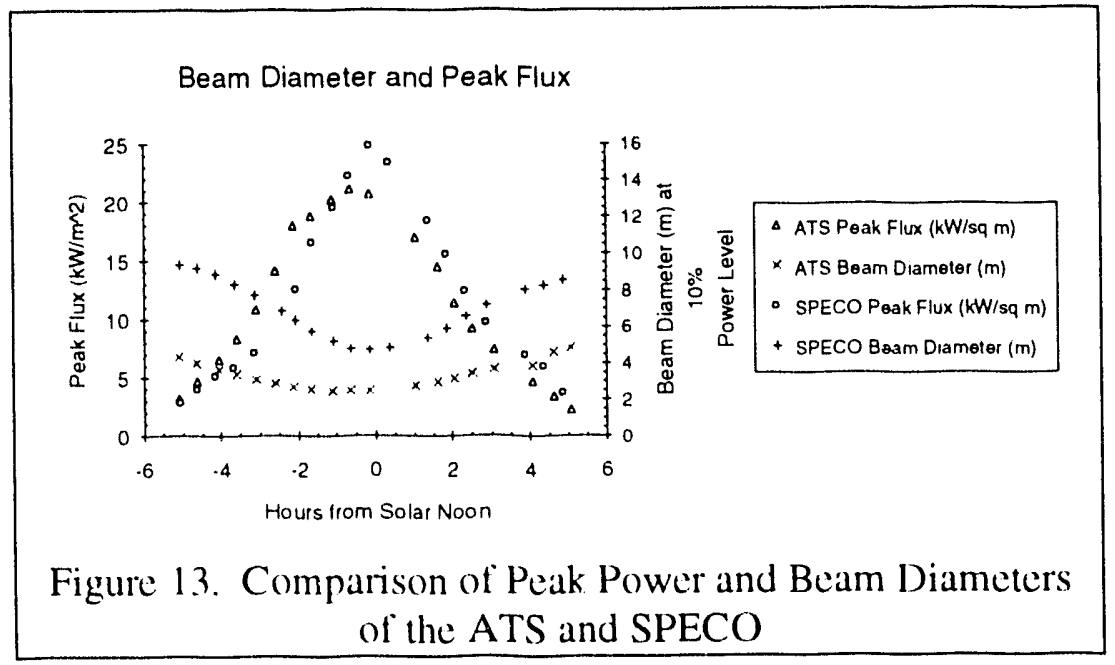


The SPECO heliostat's optical performance was less than one might have expected for a number of reasons. First, the use of lower quality glass mirrors resulted in a solar averaged reflectivity that was 11 percentage points lower than that of the ATS mirrors (initial solar averaged reflectivity of the SPECO mirrors was $83 \%$; ATS mirrors were $94 \%$ ). To examine the performance of the heliostats in the absence of this effect, the total beam power data plotted in Fig. 12 was further normalized by dividing each heliostat's performance values by the heliostat reflectivity measured at the time of the test. The results are plotted in Fig. 14.

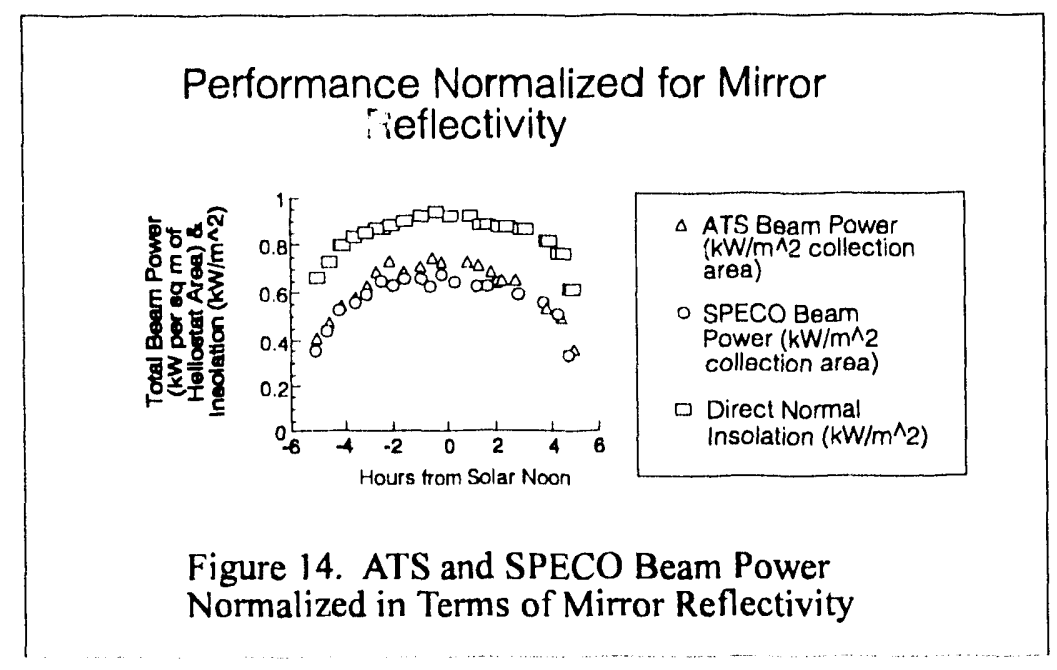

Second, the canting (aiming) of the SPECO mirror modules was not optimized (as were those of the ATS heliostat); a realignment of the modules would almost certainly reduce the nominal beam diameter.

Finally, another likely contributor to overall slope error in the SPECO mirror modules relates to the position of the module-mounting studs on the mirrors. These studs attach the mirror to the metal frame of the mirror module; they are adjusted to set the curvature of the mirror. There are nine studs on each mirror, spaced evenly in a rectangular pattern approximately $30 \mathrm{~cm}$ from the edges of the mirror. This means that about 5()$\%$ of the mirror area lies to the outside of the stud pattern. A consequence of this is that the curvature obtained in the mirror surface areas to the outside of the stud pattern is less than that obtained for the interior area. 


\section{Modeling the Beam Quality of the Large-Area Heliostats}

The measured performance of the large-area heliostats was compared to performance predictions generated hy HELIOS 11 ], a computer code for modeling the optical performance of concentrators. The comparison was obtained by varying the input slope error ${ }^{12}$ to the HELIOS model until the predicted measurement had been made. The results of the computer runs are plotted together with the measured beam profiles in Figs. 15 and 16. In the case of the ATS heliostat, an overall heliostat slope error of $1.2 \mathrm{mr}$ (as an input parameter for the HELIOS run) was found to provide a reasonable match between the predicted and measured beam centroid proliles at or near solar noon. An input slope error of $2.0 \mathrm{mr}$ was required in the HELIOS model to obtain a good match for the morning measurement; this is an increase in effective overall slope error over the noon time of about $(0.8 \mathrm{mr}$.

Modeling of the SPECO's performance (Fig. 16) indicated that an overall slope error of $2.2102 .5 \mathrm{mr}$ was a reasonable estimate for the SPECO heliostat at or near the solar noon-time. Matching of the HELIOS model to the measured performance outside of solar noon is required for an input slope error of $4 \mathrm{mr}$.

\section{Comments on Off-Noon Performance and Modeling}

Gravity-induced deflection is a reasonable explanation for the observed flux distribution of the heliostats (see ()8:30) a.m. contour in Fig. 8). The himodal nature of the distribution outside of solar noon is evidence that the heliostat has effectively developed two separate aim points. Moreover, the construction of the mirror module support structures and their means of attachment to the elevation drive (see Figs. 3 and 4) suggests that gravity-induced deflection ("clam-shelling" or "opening up") of the left and right sides of the heliostat is lavored when the mirror modules are in the horizontal orientation. Such deflection would result in a divergence of the beams from the left and right sides of the collector. In other words, as a heliostat's reflective surface is rotated from a vertical to a horizontal position, the left and right sides of the module support sag and the structure "opens up"; as the heliostat is lowered in elevation, the structure recovers from that deflection and "closes up." Mirror modules are canted to obtain the best beam characteristics at noontime when the heliostat's average elevation angle is approximately $34^{\circ}$ from horizontal (for Albuquerque. New Mexico). At this elevation angle, the left and right sides of the mirror module support structure have some deflection or sagging. When the heliostat is rotated toward the vertical orientation at times outside of noon, the module's support structure recovers from the gravity-induced deflection, and the aim points of the left and right sides of the heliostat cross over one another. This explanation is consistent with the observed beam quality measurements, but tests have not been performed to verify or refute the hypothesis.

\footnotetext{
${ }^{12}$ The overall slope error includes the effects of waviness (deviations of the surface on a small-scale), surface slope crrors, and canting crrors.
} 


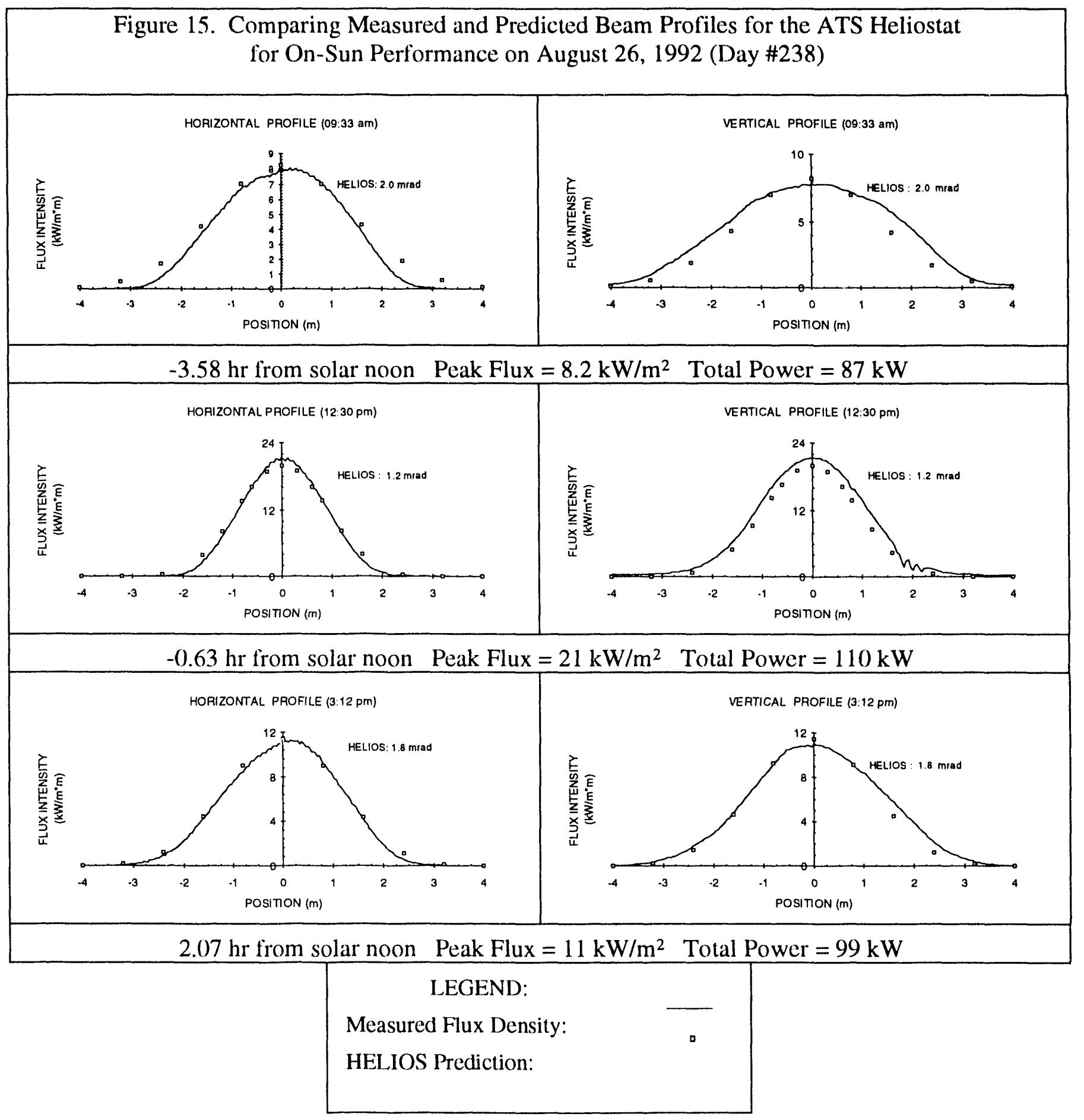




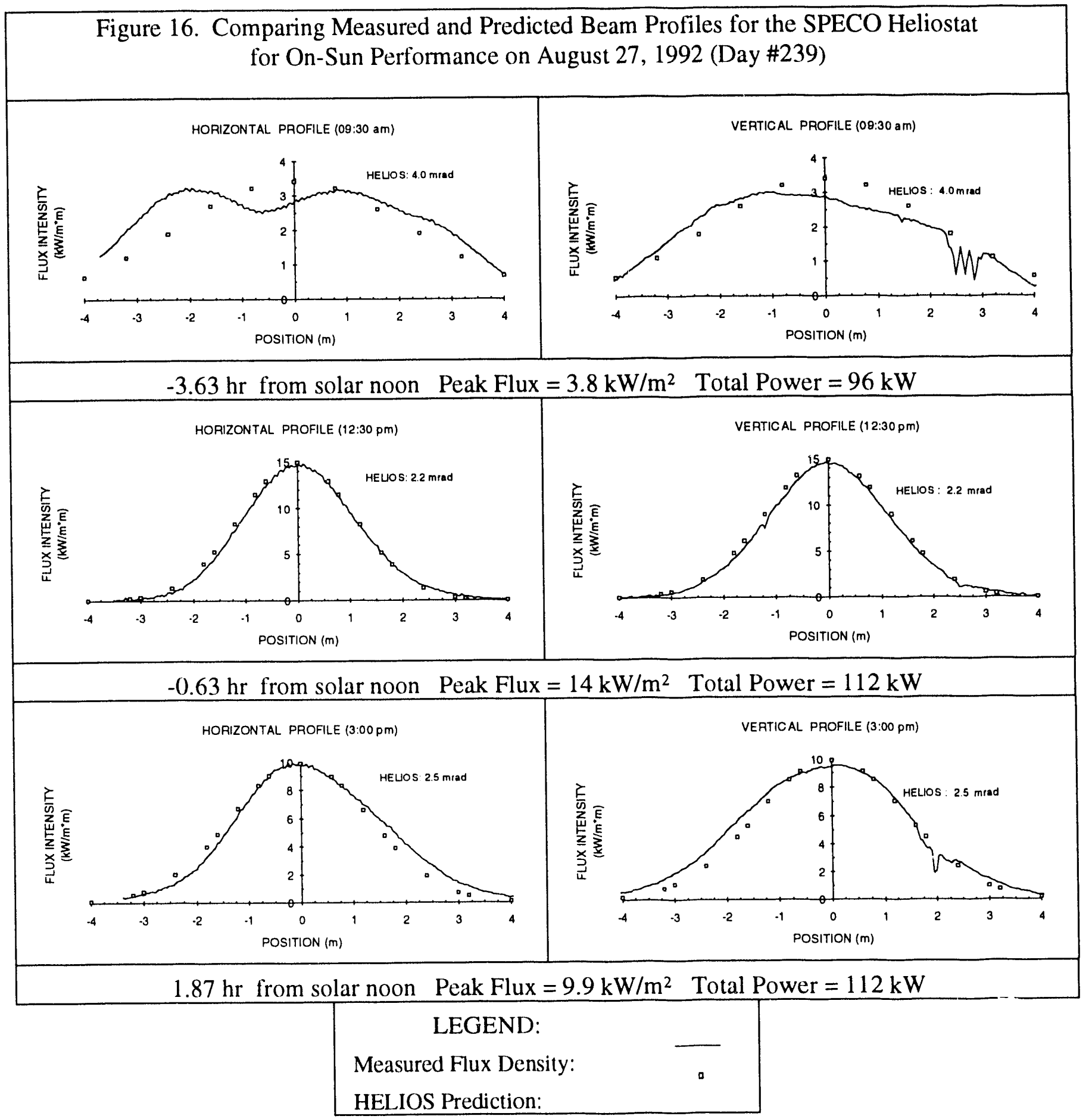




\section{Summary/Conclusions on the Beam Quality Test Results}

- On the test days discussed here, under noontime, normalized $\left(1,000 \mathrm{~kW} / \mathrm{m}^{2}\right)$ conditions, the ATS and SPECO respectively delivered up to 119 and $127 \mathrm{~kW}$ of thermal energy. On a unit basis this is 0.79 and $0.63 \mathrm{~kW} / \mathrm{m}^{2}$ of collection area for the ATS and the SPECO, respectively.

- The smallest observed beam diameter (10\% power contour line) for the ATS and the SPECO was 3.85 and $4.75 \mathrm{~m}$, respectively, and the highest measured peak flux levels of the two heliostats were 21.0 and $15.9 \mathrm{~kW} / \mathrm{m}^{2}$.

- The ATS's noontime overall slope error of $1.2 \mathrm{mr}$ (as determined by matching actual performance protiles to those generated using the HELIOS computer code) meets the second-generation heliostat design requirements[1] for beam shape ("theoretical beam shape plus $1.4 \mathrm{mr}$ fringe"). Its slope erro:s outside of sclar noon ( 1.7 to $2.0 \mathrm{mr}$ ) just exceed the requirements.

- The SPECO heliostat's noontime performance of $2.2 \mathrm{mr}$ falls short of the design requirement, and outside of noon its performance of $4 .(1) \mathrm{mr}$ exceeds the design limit by a large margin.

- The SPECO heliostat's performance would be improved by further optimizing the alignment of the mirror modules.

- The positioning of the SPECO mirror-to-module mounting studs may incur additional surface slope errors, and could be evaluated as a means to improve collector performance.

- The beam quality measurements outside of solar noon for both heliostats indicate the emergence of two separate aim points. This effect is most evident for the SPECO heliostat, which for times away from solar noon substantially exceeds the specified maximum slope error. The effect may be caused by gravity-induced deflection of the left and right portions of the mirror module support structure. The acceptability of the optical performance of either heliostat would depend on the heliostat's location (slant range and orientation) as well as the dimensions of the receiver.

\section{WIND EFFECTS}

\section{Background and Description of Test}

The large-area heliostats were designed (to the second-generation heliostat specifications) for normal operation under windy conditions up to $27 \mathrm{mph}$ |11. In the event wind gusts exceed $27 \mathrm{mph}$, the heliostats are to be sent to a stow position that minimizes wind drag on the collector. The purpose of the wind effects tests was to evaluate the effect of the wind on beam quality for high velecities within the operational limit, 
and to seek answers to a number of questions: At what wind speed levels does significant heliostat movement begin to occur? How much movement of the beam results at elevated wind speeds? What is the relationship of the angle of attack of the wind on heliostat movement? At what wind speed and for what angles of attack dees the beam quality become unaceptable from an operational standpoint? Do the wind spoilers on the SPEC() heliostat reduce wind drag?

The tools employed in the wind effects tests were the BCS and the meteorological tower. The BCS was used to observe and capture sucesssive images of the heliostat beam on the BCS target while simultaneously measuring and recording wind speed and direction. The test was performed at times when there was both sunshine ${ }^{13}$ and wind speeds were above 10 to $15 \mathrm{mph}$. The simultaneous occurrence of high winds and sunny conditions is fairly infrequent at the NSTTF, and, in addition, winds are predominantly from the west and southwest, which limited the recorded wind "events" to a fairly narrow range of angles of attack. Nonetheless, suceessful tests were carried out on several oceasions, and the results answer some questions regarding wind effects.

The BCS is employed in the wind effects test to obtain a measure of heliostat beam centroid movement during the wind event. ${ }^{14}$ For a $27-m p h$ wind, the (second-generation) specilications (see Table 1) permit a maximum mirror surface deflection of $3.6 \mathrm{mr}$ and a maximum pedestal twist or tilt of $1.5 \mathrm{mr}$. But the actual source of the heam deflection (he it pedestal twist or bend, deflection of the mirror support structure, or bending of the mirrors themselves) cannot be determined from heliostat beam movement alone. The wind effects lest only provided a measure of overall beam deflection due to the wind. Since the expected combined effect of two independent error soures is the square root of the sum of the squares of the two errors, an approximate combined specification for wind-induced beam deflection would be $3.9 \mathrm{mr} .{ }^{15}$

In the wind effects test, the BCS images are used to measure the relative movement of the beam centroid and the general shape of the heliostat beam during the observed wind event. For the purposes of the test, the average pessition of the heliostat heam during the test is taken so be the desired aim point. This is not precisely the case, but is a reasonable approach since wind events cannot be predicted in advance, and in most cases the "actual" heliostat aim pxint on the BCS target has not been established prior to the onset of

\footnotetext{
${ }^{13}$ Since the wind effect was measured by observing heliostat beam movement with the BCS, sunshine is a required condition for the test. lully clear conditions, however are not essential.

${ }^{14} \wedge$ valid flux map of the heliostat beam is not possible since the wind-induced movement of the heam "smears" the tlux measurements obtained from the gatuge on the BCS larget.

$15.3 .9=\sqrt{(3.6)^{2}+(1.5)^{2}}$
} 
the test. A consequence, however, is that this test does not measure any constant offset of the average beam position during the wind event (constant offset compared to the average beam position when there is no wind).

The wind effects test was performed using the image analysis system's fastest image-capture rate (0.1 seconds per image) and taking the greatest number of images possible. Some image series were taken at full camera resolution, which resulted in 48 images and a 4.8 second time series; others were taken at haif resolution, resulting in 192 images and a 19.2 second series. The digitized images of the beam and the associated wind data were then saved for later analysis.

\section{Results and Discussion}

To illustrate the wind-induced beam movement that was observed during the wind effects tests, Fig. 17 provides a polar plot of the (SPECO) heliostat beam's centroid movement. In the plot, the successive locations of the beam centroid are marked with a cross; each cross is labeled with its associated imagecapture time in seconds. The beam centroid movement during a representative interval of the 20 -second period of BCS image data capture can in this way be observed. The movement observed during this particular wind event was the maximum beam movement observed in all the tests. The average wind speed during the event was $18 \mathrm{mph}$, and the wind's angle of attack (AOA, the angle between the wind direction and the vector normal to the surface of the heliostat) was $150^{\circ}$ (i.e., the wind was coming from the back of the

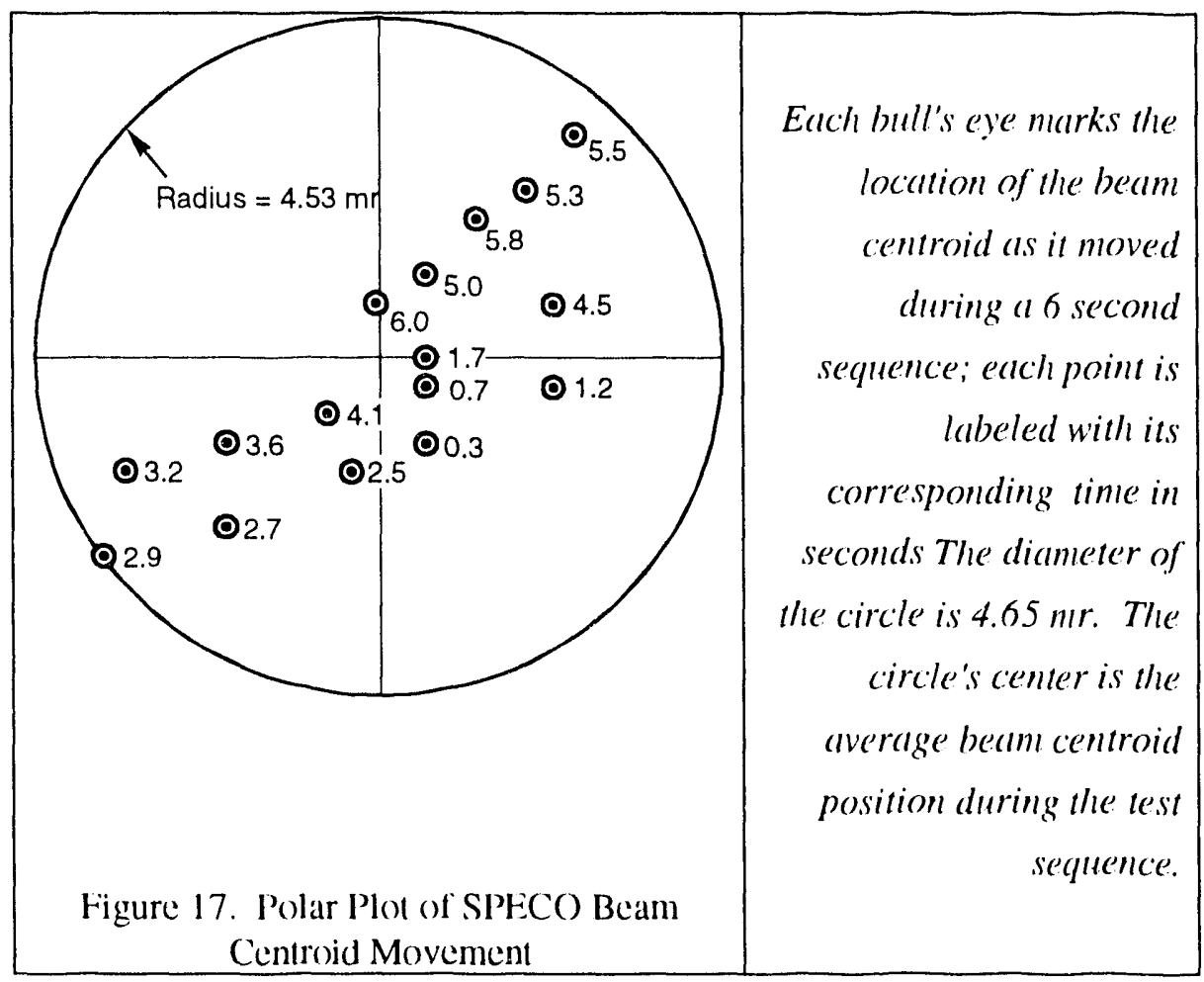


heliostat). The average movement of the beam eentroid was $1.8 \mathrm{mr}$ during the 20-second time interval recorded, and the maximum was $4.65 \mathrm{mr}$. (4.65 is also the radius of the circle in the polar plot.)

Because of the predominance of west to southwesterly winds at the test site, the wind effects tests were performed in a fairly narrow range of AOA: for the ATS heliostat, the AOA for all tests was between $92^{\circ}$ and $111^{\circ}$; for the SPECO, it was between $1\left(14^{\circ}\right.$ and $150^{\circ}$. The absence of test data for "head on" AOA (an $\mathrm{A}\left(\mathrm{)A}\right.$ of or near ()$^{\circ}$ or 18()$\left.^{\circ}\right)$ is unfortunate since one would expect to observe maximum wind drag at these angles. A description of the data obtained and a summary of the results are provided in Table 5.

Although similar trends were observed for hoth heliostats, the test data obtained is probably insufficient to draw firm conclusions. The wind effects data for the two heliostats is presented in Figs. 18 and 19. There is considerable scatter in the dati, and although clear trends are difficult to infer, linear curve fits of the data are also presented in the figures.

Most of the wind effects data obtained were for AOA clese to 90$)^{\circ}$, i.e., with the wind parallel or nearly parallel to the heliostat surface, i.e., heam deflection under "head on" AOA was not measured. The observations that were made were at angles closer to perpendicular to the collector surface. The moment coefticients for shallow angles of attack are expected to be greater and should produce a greater dynamic response. The results suggest that heam movement will remain within heliostat specifications. In an 18 mph wind, with an AOA of 15$)^{\circ}$, the SPECO heliostat's maximum beam movement of $4.7 \mathrm{mr}$ did exceed the 3.9-mr (second-generation design) specilication. The average beam deflection of $1.8 \mathrm{mr}$, however, was well within specified limits. In a $27-\mathrm{mph}$ wind, with an AOA of $111^{\circ}$, the ATS heliostat's maximum beam deflection was $3.2 \mathrm{mr}$, while its average was $1.6 \mathrm{mr}$. Thus, the data that was obtained, though perhaps

\begin{tabular}{|l|l|l|}
\hline \multicolumn{2}{|c|}{ Table 5. Summary of Wind Effects Test Results } \\
\hline & ATS Heliostat & SPECO Heliostat \\
\hline Number of recorded events & 11 & 10 \\
\hline Range of wind speeds: & $111027 \mathrm{mph}$ & $121026 \mathrm{mph}$ \\
\hline Range of angles of atlack: & $92^{\circ} 10111^{\circ}$ & $1\left(14^{\circ} 10150^{\circ}\right.$ \\
\hline $\begin{array}{l}\text { Maximum observed heam } \\
\text { deviation: }\end{array}$ & $\begin{array}{l}3.7 \mathrm{mr} \\
\left(\text { at } 20.7 \mathrm{mph} \& 92^{\circ}\right.\end{array}$ & $\begin{array}{l}4.7 \mathrm{mr} \\
(\text { at } 17.7 \mathrm{mph} \& 15)^{\circ} \\
\mathrm{AOA})\end{array}$ \\
\hline $\begin{array}{l}\text { Average deviation of beam } \\
\text { centroid deviation for all } \\
\text { observations }\end{array}$ & $(1.92 \mathrm{mr}$ & $(1.86$ \\
\hline $\begin{array}{l}\text { Average maximum beam } \\
\text { centroid deviation for all } \\
\text { ohservations }\end{array}$ & $1.9 \mathrm{mr}$ & 1.9 \\
\hline
\end{tabular}


Silmmary of ATS Wind Effects Data
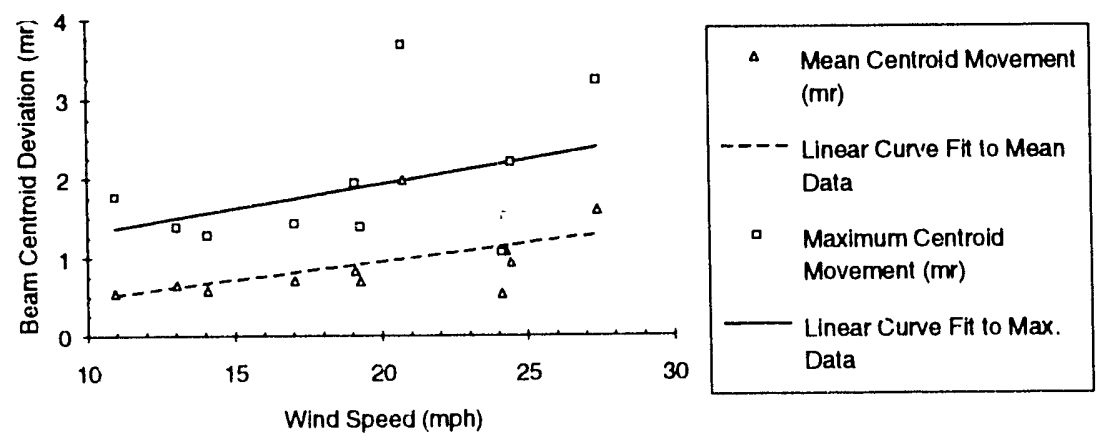

Figure 18. Effect of Wind on ATS Heliostat Beam Position

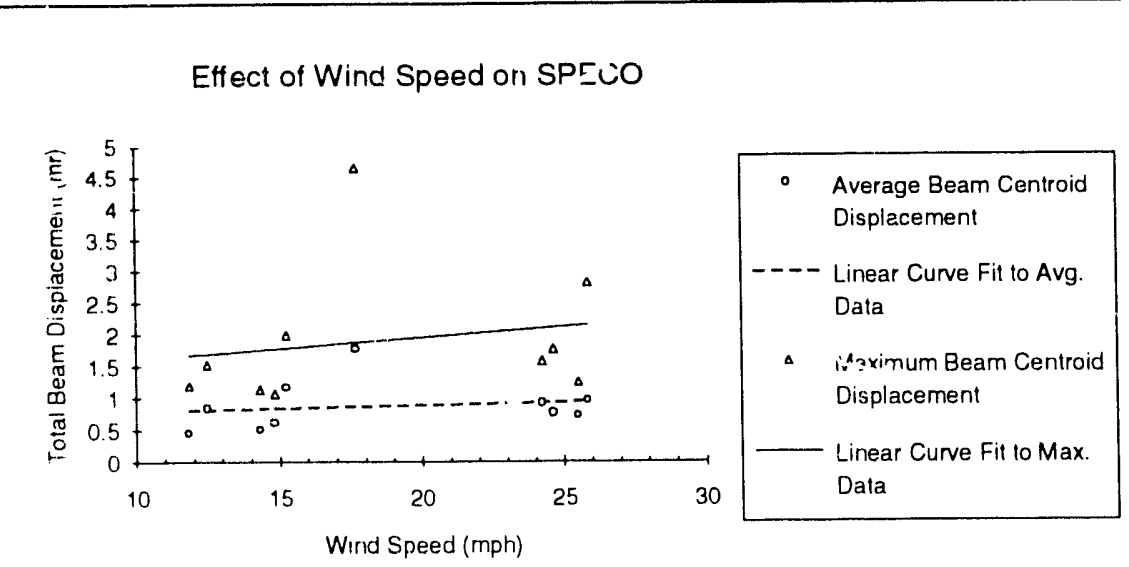

Figure 19. Efiect of Wind on SPECO Heliostat Beam Pos tion

insufficieri, suggests that the large-area heliostats will perform within second-generation specifications in terms of their average wind-induced beam deflection.

Figure 20 provides a side-by-side comparison of the linear curve fits of beam movement for the two heliostats. (Given the greal degree of scatter in the original data, the linear curve fits are not particularly meaningful, but the plot does illustrate the similarity of the performance of the two heliostats. The nearhorizontal slope of the SPEC() curves are intriguing given the fact that the heliostat's wind spoilers were intended to dampen out the structure's response to the wind! Although the number of observations made was limiied, they suggest that the wind spoilers do dampen heliostat response at higher wind speeds. 


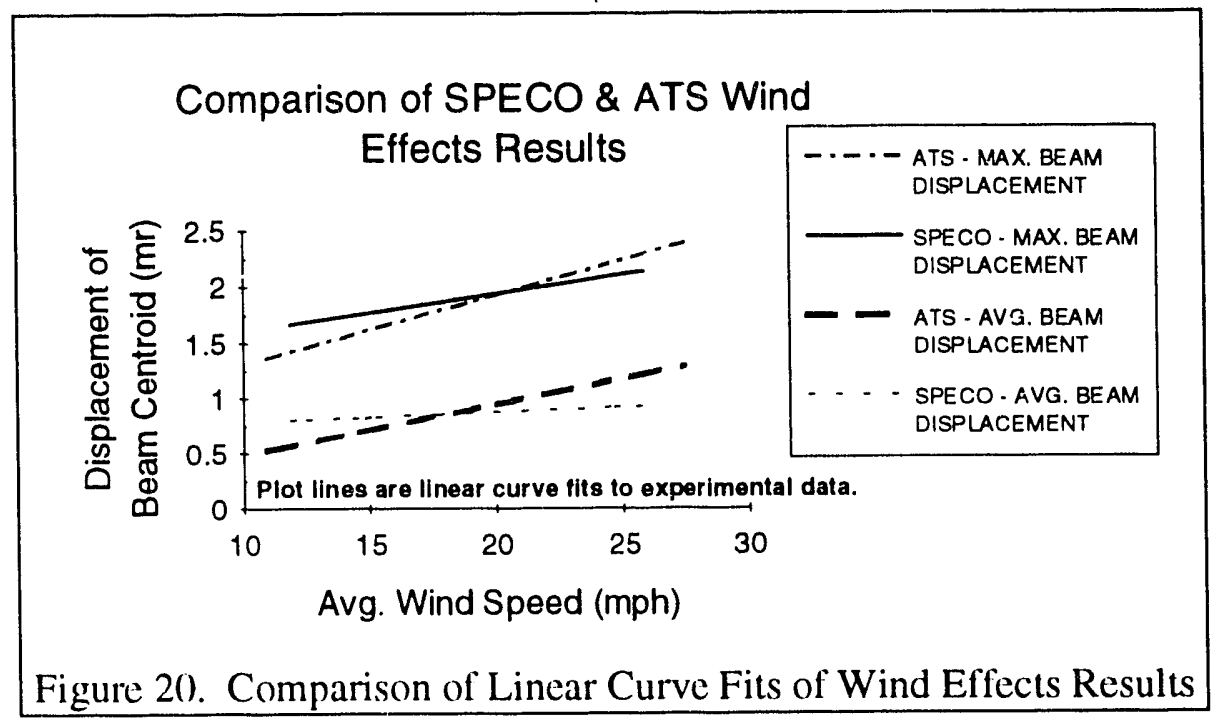

\section{Conclusions}

- For both large-area heliostats, the observed deflection of the collector beam in winds from 12 to $27 \mathrm{mph}$ remained within specifications for the second-generation heliostat design. The average beam centroid movement was $(1.9 \mathrm{mr}$, and the average maximum movement was $1.9 \mathrm{mr}$.

- The observations that were made suggest that the heliostats will perform within second-generation design specifications in terms of their average wind-induced beam deflection.

\section{Heliostat Drive and Control Systems}

\section{OPERATIONAL CHARACTERISTICS OF THE DRIVE SYSTEMS}

The drive systems of the two heliostats were evaluated in terms of standard operation, power consumption, slew rates, and drive control repeatability. During all the tests, ambient temperatures were in the range of $95^{\circ} 1098^{\circ} \mathrm{F}$, and wind speeds were 5 to $8 \mathrm{mph}$. All of the ATS results presented here pertain to the lowcost drive. ${ }^{16}$

\section{Slew Rates}

The average slew rate (results summarized in Table 6) for the two heliostats was around $.21^{\circ}$ per second. The rate varied only slightly for the heliostats in different modes of operation (such as driving upward in elevation or combined driving in azimuth and elevation).

\footnotetext{
16'The original drive manufactured by $\Lambda$. (i. Flender was replaced with the Winsmith Low-Cost drive as explained above.
} 


\begin{tabular}{|l|l|l|}
\hline \multicolumn{3}{|c|}{ Table 6. Large-Area Heliostat Slew Rates } \\
\hline \multicolumn{1}{|c|}{ Slew Rates in degrees per second } & ATS & SPECO \\
\hline Azimuth slew rate: & .20 & .22 \\
Elevation down rate: & .21 & .22 \\
Elevation up rate: & .22 & .18 \\
Combined rates, elev. drive down: & & \\
$\quad$ Azimuth: & .21 & .22 \\
Elevation: & .21 & .22 \\
Combined rates, elev. drive up: & .20 & .21 \\
Azimuth: & .21 & .18 \\
Flevation & & \\
\hline
\end{tabular}

\section{Power Consumption}

Table 7 summarizes the results of tests to evaluate both the instantaneous power draw of the drives as well as the power consumption during a typical (1)-hour) day of heliostat operation. The measurements were made with an AC walt-hour (WH) meter. ${ }^{17}$ The all-day power consumption of the ATS and SPECO, respectively, was measured at 292 and 38.5 watt-hours. This included heliostat movement from horizontal stow to on-sun tracking of a target, tracking of target for $10 \mathrm{hr}$, and then returning to the horizontal stow position. The test demonstrates the inefficiency of worm gear drives (employed by the SPECO heliostat); however, they have the advantage of high strength, large gear reduction in a single stage, anti-backdriving capabilitics, and low cost.

\section{Control Drive Repeatability}

A group of tests was performed to evaluate the repeatability of the drive's control system; the results are summarized in Table 8 . The first test consisted of commanding the heliostat to drive $45^{\circ}$ in azimuth and $30^{\circ}$ in elevation away from a starting position and then to return to the original starting position. To determine control drive repeatability, an independent measurement of the heliostat's position before and after the

\begin{tabular}{|l|l|l|}
\hline \multicolumn{3}{|c|}{ Table 7. Power Utilization of the Large-A rea Heliostats } \\
\hline \multicolumn{1}{|c|}{ ATS: } & \multicolumn{1}{|c|}{ SPECO: } \\
\hline Quiescent Power: & $10 \mathrm{~W}$ & $14 \mathrm{~W}$ \\
Avg. Power Draw (both drives) & $35-75 \mathrm{~W}$ & $20(0)-30() \mathrm{W}$ \\
Avg. Power Draw (elev. drive) & $22-35 \mathrm{~W}$ & 120 \\
Typical peak draw (both drives) & $175 \mathrm{~W}$ & $470 \mathrm{~W}$ \\
On-sun tracking: & $80 \mathrm{~W}$ (average) & $140 \mathrm{~W}$ (average) \\
All-day power consumption & $292 \mathrm{WH}$ & $385 \mathrm{WH}$ \\
\hline
\end{tabular}

${ }^{17}$ Model WH3-14, manufactured by Ohio Semitronics, Inc. 
Table 8. Large-Area Heliostat Drive Control Repeatability

\begin{tabular}{|l|l|l|}
\hline \multirow{2}{*}{ Move away \& return to original position: } & ATS: & SPECO: \\
\cline { 2 - 3 } $\begin{array}{l}\text { Lose power, re-calibrate encoders, \& return to } \\
\text { original position: }\end{array}$ & $1.3+/-0.1 \mathrm{mr}$ & $0.5+/-0.1 \mathrm{mr}$ \\
\hline
\end{tabular}

commanded movement was made using a laser beam. With the heliostat in its starting position, a laser mounted on the mirror support structure was aimed on a paper target positioned about $50 \mathrm{ft}$ from the heliostat. The initial location of the laser beam on the paper target was marked at the outset of the test and after each "round trip" of the heliostat. Differences in the laser beam position represent repeatability error of the heliostat drive. A variation of this test involved commanding the heliostat to drive past the home position and then return to it.

A second test involved repositioning the heliostat after executing a sequence of commands that simulated power loss to the heliostats. After the simulated power loss, the heliostats were commanded to go to the "wake" position, which causes a resetting of the drive motor encoders, and then to return to the "home" or reference position. The same laser mounted on the heliostat (as described above) was used to measure the difference between the original laser beam position on a target and its position in repeated iterations of the test sequence. For this test, an average repeatability error of $0.97 \mathrm{mr}$ and $0.64 \mathrm{mr}$ was observed for the ATS and SPECO heliostats, respectively.

The results of these tests indicate that the SPECO's drive system achieved better repeatability, although the performance of both heliostats is acceptable in terms of second-generation design specifications.

\section{LIFE-CYCLE TESTING}

The drives of the two large-area heliostats were exercised in order to give them accelerated use and wear. This practice was initiated after the installation of the low-cost drive on the ATS heliostat, and the accelerated life-cycling information given here is pertinent to the low-cost drive and not to the A.G. Flender drive (see related comment on the ATS drive). The accelerated life cycling was carried out by the use of batch command files executed by the heliostat computer control program. This feature of the computerbased control system permitted the sequential, unattended execution of drive commands. A typical cycle in a batch command file would drive the heliostat through the range of movement in azimuth and elevation that it would normally experience in a day of operation at a central receiver plant. The drive would command the heliostat from its normal morning sun-tracking position all the way to its normal evening position, and then pause for several minutes to allow the drive motor to cool before returning again to the morning position. 
The batch command file consisted of multiple repetitions of this sequence; by this means, a number of equivalent years of heliostat operation was obtained.

The azimuth and elevation drive-cycling was performed separately. The elevation drive was cycled during the nighttime only so as to avoid tracking the potentially hazardous heliostat beam: up and down through the heliostat field during the day. The azimuth cycling was carried out at any convenient time; a result of this was that more azimuth than elevation drive life-cycles were carried out.

During the period from April 1990) to August 1991, the ATS (Winsmith low-cost drive) received an equivalent of 4.22 years $^{18}$ of operation of the azimuth drive and 2.98 years of operation of the elevation drive; the SPECO's (Hub City) azimuth drive received 3.36 years and its elevation drive received 2.58 years of operation. ${ }^{19}$ The life-cycling information is reproduced in Table 9.

No failures of either drive system were experienced during this time.

\begin{tabular}{|l|l|l|}
\hline \multicolumn{3}{|c|}{ Table 9. Summary of Life Cycling Data for Large-Area Heliostats } \\
\hline & \multicolumn{1}{|c|}{ ATS } & \multicolumn{1}{c|}{ SPECO } \\
\hline Elevation Drive Cycles** & 1086 & 943 \\
\hline Azimuth Drive Cycles & 154() & 1226 \\
\hline
\end{tabular}

** 1 cycle $=1$ day of normal operation

\section{TRACKING ACCURACY TESTS}

Both the SPFCO and ATS heliostats employed a prototype heliostat control system ${ }^{20}$ which has a tracking deadband that is set in the software by the operator. The control system initiates movement of the heliostat drives only when the positional error exeeeds the specified deadband. In an evaluation of this aspect of the tracking controls, the RMS tracking error of the azimuth and clevation drives, respectively, was measured at 0.5() and ().35 (+/- ().1) mr when the tracking deadband was set at its minimum value, $0.1745 \mathrm{mr}$. The test data is plotted in Fig. 21.

All-day tracking error tests were performed on the two heliostats in order to measure the overall tracking error over a period of several days. larger than expected tracking errors with the ATS prompted

\footnotetext{
${ }^{18} A$ year of operation defined as 365 cycles.

"This cycling of the SPI:C () occurred after the failure and repair of the drive unit, which is discussed below.

${ }^{20}$ See description of the prototype heliostat control system in Section 2, "I Iescription of the Large-Area Heliostats."
} 


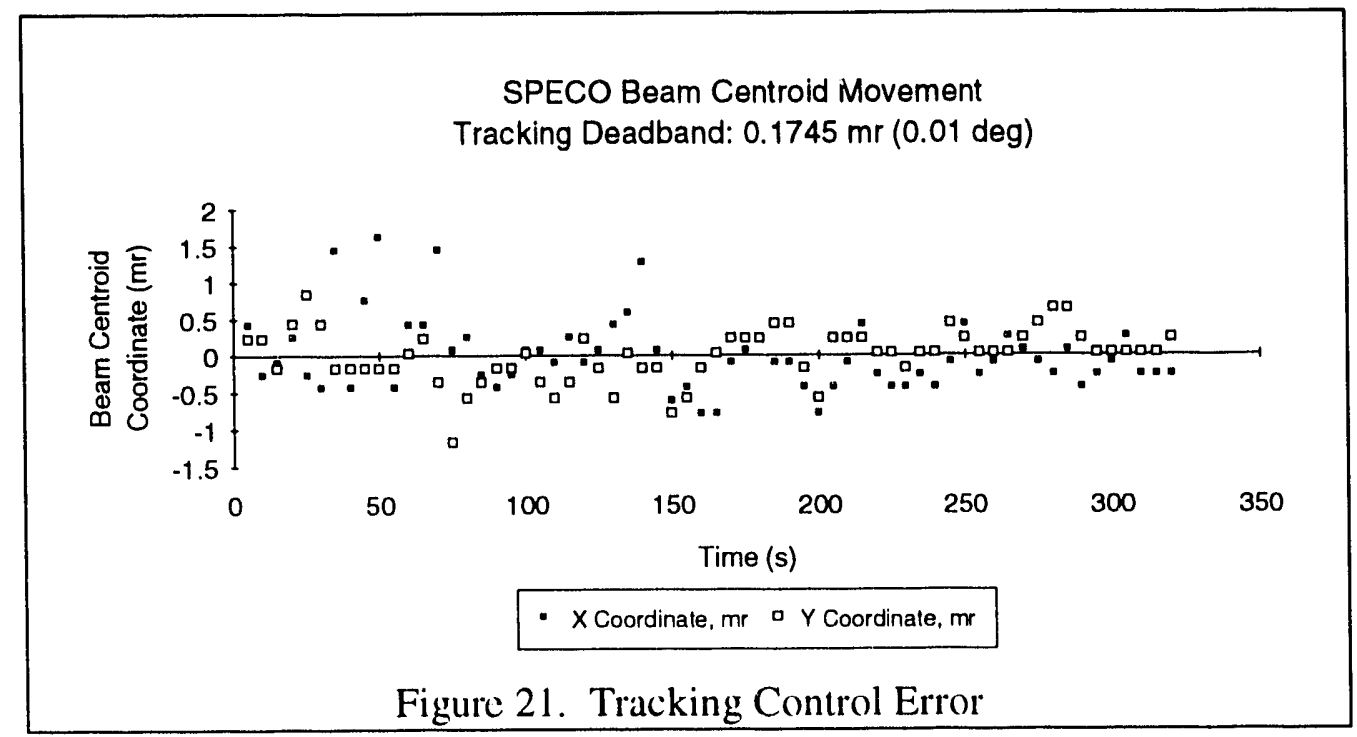

investigation and led to the discovery of an intermittent malfunctioning of the ATS's elevation drive encoder. Because the tracking tests were concluded prior to the repair of the ATS encoder, the results presented here are for the SPECO heliostat.

For these tests, the BCS was employed in the test to observe and record the location of the SPECO heliostat's beam centroid at 2()- to 30-minute intervals as it tracked the BCS target over a 6-day period. Differences between the observed location of the beam eentroid and the coordinates of the aim-point were the measure of overall tracking error.

The all-day tracking error tests revealed systematic tracking errors that increased linearly as a function of time from solar noon. There was evidence of substantial pedestal tilt errors ${ }^{21}$ which were probably a consequence of the earlier failure of the SPECO drive (described in the next section). The average magnitude of the tracking error of the SPECO during the all-day tracking tests was $1.65(+/-0.25) \mathrm{mr}$; a maximum error of $3.9(+/-(0.25) \mathrm{mr}$ was observed 4 hours after solar noon.

Because the prototype heliostat control system is capable of compensating for pedestal tilt error, an analysis of the all-day tracking error test data was performed in order to differentiate the linearly occurring tracking error, which could have been eliminated by inputting pedestal tilt data into the control system. When the systematic linear error of the test data was subtracted out, what remained was an RMS tracking error of ().83 and $(0.28(+/-0.1) \mathrm{mr}$, respectively, for the azimuth and elevation drives. This result, though not exhaustive, provides a reasonable representation of tracking error for the SPECO heliostat. The test results

\footnotetext{
${ }^{21}$ Pedestal tilt errors are those resulting from the pedestal not being perfectly vertical.
} 
compare favorably with the Second Generation Heliostat Design Requirements (Table 1), which specify a maximum RMS tracking error of $1.5 \mathrm{mr}$ for each drive.

\section{FAILURE AND REMANUFACTURE OF THE SPECO DRIVE}

In a winter storm in early 1988, the SPECO's drive unit, which was manufactured by Hub City, Inc., was damaged by winds [12]. Because of general power outages that occurred at the time of the failure, the exact time of failure and the wind speed at which the failure occurred are unknown. Likewise, it could not be determined if the failure occurred at winds above the design-specified 90-mph (stow position) survival wind.

Upon inspection, several broken teeth were discovered in the (elevation) bronze worm gear that had been cast onto the steel hub of the drive. Moreover, the bronze casting was found to have significant surface imperfections due to the casting process.

A second hub manufactured at the same time as the original was installed in the drive was then returned to Sandia. X-rays taken of the worm gear through the housing revealed similar surface imperfections in the bronze worm gear casting, but showed no large voids or other problems. During torsional load tests, one of the worm gear teeth fractured and a second one cracked. The subsequent analysis resulted in several design changes to the gear and its recasting. The worm gear was recast (at a different foundry) and the remanufactured gear passed subsequent X-ray examination and load testing, and was re-installed on the SPECO heliostat. The drive performed satisfactorily through the remainder of the test period.

\section{FAILURE AND MODIFICATION OF THE LOW-COST HELIOSTAT DRIVE [13]}

In June 1988, a low-cost heliostat drive specifically developed for heliostats under DOE sponsorship was installed for evaluation on the ATS heliosta (this drive is described in Table 2). On January 9, 1989, during a period of severe cold, the azimuth drive unit failed structurally, resulting in the detachment of the heliostat from the pedestal.

The failure of the azimuth drive was caused by water, which seeped into the azimuth drive cavity. The water, together with the drive's lubricating grease, completely filled the cavity and then froze. The freezing process began at the outside surfaces and traveled inward, sealing off any escape route for fluid. The expansion of the water as it froze increased the internal pressure; eventually the hydraulic pressure was sufficient to shatter the outer housing of the azimuth drive, and with it the support for the outer race for the main support bearing. The entire mirror structure then tilted and caused further damage to the azimuth drive. 
Careful inspection of the failed drive led to the conclusion that water penetrated the cavity around the bolts that fasten the elevation drive unit to the top of the azimuth unit. Several of these bolts were found to be loose, with evidence of associated water corrosion in the bolt holes. These bolt holes are located radially to the inside of an outer sealing o-ring. As a result, any water leaking through them would have a direct path down into the azimuth drive cavity.

A design modification was made to provide an additional sealing ring radially to the inside of that bolt circle. The use of Loctite was also proposed to insure secure tightening of the bolts. (Lockwiring of the bolts was suggested as an alternative.) A drive unit with these modification was re-installed on the ATS heliostat and operated satisfactorily (and with no failures) for the balance of the evaluation period. 


\section{SUMMARY AND CONCLUSION}

\section{Heliostat Costs}

- A 1988 cost estimate for the manufacture of large-area heliostats (at a rate of 2,500 per year) set the cost (1991\$) at $\$ 141 / \mathrm{m}^{2}$ of collector area.

\section{Mirrors}

- Mirror Module Reflectivity: slight degradation of mirror reflectivity was observed over a period of 6 years in both the ATS and the SPECO mirror modules; the average degradation rate for both heliostats was 0.6 to $0.7 \%$ per year. Stabilization of the reflectivity during this time period was not observed.

- Mirror Soiling: in the environment of Albuquerque, New Mexico, mirror reflectivity was observed on the average to decrease from 6 to $9 \%$ due to module soiling when no mirror cleaning was performed and the only cleaning action was that provided naturally by rain, snow, and wind action.

\section{Mirror Module Durability}

- Both heliostats' mirror modules have demonstrated durability. After five years at the New Mexico test site, small flakes of the protective paint at the edges of approximately one-quarter of the SPECO mirrors were peeling. Corrosion of the mirroring was evident at these very small and localized edge areas.

- After five years, the mechanical integrity and condition of the mirror modules were excellent: the adhesives used to bond the glass and metal parts of the module showed no signs of debonding or decomposing, and the threaded studs, hat sections, and other metal parts remained free of rust or corrosion. $^{22}$

- Heliostat designers should consider the issue of snow removal from heliostat collection surfaces. Structural elements having a physical proximity to the outer edges mirror array have the potential to trap snow on the mirrors, leading to possible mirror breakage.

\section{Beam Characterization}

- Al times outside of solar noon, the optical performance of both collectors is hampered by the divergence of the beams from the left and right sides of the heliostat. This effect is most evident with

\footnotetext{
${ }^{22}$ In fairness, it should he pointed out that Albuquerque, New Mexico is a fairly dry climate; outdoor metal structures do not in general suffer speedy rust and corrosion.
} 
the SPECO heliostat. It may be caused by gravity-induced deflection of the heliostats, which would indicate insufficient stiffiness of the mirror module support structures. The BCS test results alone are insufficient to confirm this hypothesis.

\section{ATS Heliostat Beam Quality}

- During a three-hour period centered around solar noon, the average total beam power of the SPECO (normalized to an insolation level of sun or $1 \mathrm{~kW} / \mathrm{m}^{2}$ ) was $115 \mathrm{~kW}$; titis amounts to $0.77 \mathrm{~kW} / \mathrm{m}^{2}$ of collection area. The average peak flux and beam diameter (actual measured values) during this same interval were $18.5 \mathrm{~kW} / \mathrm{m}^{2}$ and $4.1 \mathrm{~m}$, respectively, with an uncertainty of $+/-6$ to $10 \%$.

- For noontime performance, the estimated overall slope error of the ATS collector (based on comparisons of the actual beam profiles with those predicted by the HELIOS code) is $1.2 \mathrm{mr}$. The expected error in this comparison of measured and modeled performance is approximately ().5 mr. This value meets the second-generation heliostat design specification of $1.4 \mathrm{mr}$ (see Table 1). During off-nown conditions the slope error increases to approximately 1.8 to 2.0$) \mathrm{mr}$, a value slightly in excess of the specification. The expected error in this comparison of measured and modeled performance is approximalcly $(1.5 \mathrm{mr}$.

\section{SPECO Heliostat Beam Quality}

- During a three-hour period centered around solar noon, the average total beam power of the SPECO (normalized 10 an insolation level of sun or $1 \mathrm{~kW} / \mathrm{m}^{2}$ ) was $124 \mathrm{~kW}$; this amounts to $0.62 \mathrm{~kW}$ per square meter of collection area. The average peak flux and beam diameter (actual measured values) during this same interval were $13.8 \mathrm{~kW} / \mathrm{m}^{2}$ and $5 .() \mathrm{m}$, respectively, with an uncertainty of $+1-6 \mathrm{to}$ $10 \%$.

- For noxntime performance, the estimated overall slope error of the SPECO collector (based on the HEIIOS code) was $2.2 \mathrm{mr}$. The expected error in this comparison of measured and mokeled performance is approximately $(0.5 \mathrm{mr}$. This value exceeds the second-generation heliostat design specification of $1.4 \mathrm{mr}$ (see Table 1). During off-noon conditions the slope error increases to approximately $4 \mathrm{mr}$, a value considerably in excess of the specification.

- The SPEC(O) heliostat's performance would be improved by realignment of the mirror modules.

- The positioning of the SPEC() mirror-to-module mounting studs may incur additional surface slope errors, and could be evaluated as a means to improve collector performance. 


\section{Wind Effects}

- In terms of their average wind-induced beam deflection, both heliostats appear to be structurally stiff enough to perform within specilications under design wind conditions ( $27 \mathrm{mph}$ or less).

- For both heliostats, the average measured heliostat beam deflection in winds from 12 to $27 \mathrm{mph}$ was $0.9(+/-0.25) \mathrm{mr}$ while the average maximum movement was $1.9(+/-0.25) \mathrm{mr}$. Some wind-induced beam movements did exceed the 3.9-mr beam pointing error specification.

- No observations were made at wind angles of attack of (or close to) ()$^{\circ}$ or $180^{\circ}$ (wind perpendicular to face or back of collector). This leaves unexplored an important region of the design space.

\section{Operational Characteristics of the Drive Systems}

- Slew Rates: the average slew rate for both heliostats was around $.21^{\circ}$ per second, and proved to be adequate. The rate varied only slightly during different modes of operation.

- ATS Power Utilization: the ATS heliostat consumed 292 watt-hours during a typical day of operation involving 10 hours of on-sun tracking. The average power draw of the drives was found to be 35 to $75 \mathrm{~W}$ for simultaneous operation of the drives, and 22 to $35 \mathrm{~W}$ for operation of the elevation drive only.

- $\quad$ SPECO Power Utilization: the SPECO's all-day power consumption was $38.5 \mathrm{~W}$; the average power for operation of both drives was 20() $\mathrm{W}$, and about $120 \mathrm{~W}$ for operation of the elevation drive only.

\section{Drive Control Repeatability}

- In several tests measuring the ability of the heliostat drive control system to drive off of and then return to a specilic position, an average repeatability error of $(0.5$ and $1.3 \mathrm{mr}$ was measured for the SPECO and ATS, respectively. (Measurement uncertainty was $+/-() .1 \mathrm{mr}$.)

- Tests involving the return of the heliostat to a specified position following the (simulated) loss of power resulted in repeatability measures of (0.97 and ().64 $\mathrm{mr}$ for SPECO and ATS, respectively. (Measurement uncertainty was $+/-(), 1 \mathrm{mr}$.)

\section{Life-Cycle Testing}

- The drive systems of hoth heliostats survived life-cycle testing without failures. The elevation drives of the ATS and SPEC(), respectively, received 3.() and 2.6 years of life-cycling, while their azimuth drives received 4.2 and 3.4 years, respectively. 


\section{All-Day Tracking}

- Tracking error data was obtained for the SPECO heliostat, but not for the ATS heliostat (which was equipped with the low-cost drive).

- The tracking error of the prototype heliostat control system was determined experimentally to be 0.50 and $0.35(+/-() .1) \mathrm{mr}$, respectively for the azimuth and elevation drives when the control system's tracking deadhand was set at the minimum permissible value, (0.174.5 mr.

- Based on analysis of all-day tracking test data, the overall RMS tracking error of the azimuth and clevation drives, respectively, was found to be $(0.83$ and $(0.28(+/-() .15) \mathrm{mr}$, and compares favorably with the Second (ieneration Heliostat Design Requirements (Table 1) which specify a maximum RMS tracking crror of $1.5 \mathrm{mr}$ for each drive.

\section{Failure and Remanufacture of the SPECO Drive}

- The failure of the SPEC() drive led to the discovery of design and manufacturing faults in the bronzecast worm gear. A detailed report on this is given by (irossman |12|.

- Alter its redesign and manufacture, the SPEC() drive performed well and experienced no further failures.

\section{Failure and Redesign of the Low-Cost Heliostat Drive}

- A failure of the Pecrless-Winsmith drive in June 1988 led to the discovery of a design flaw that permitted the penetration of water into the azimuth drive cavity. After modifications to the design, a new drive unit was manufactured and operated satisfactorily for the balance of the evaluation period. 


\section{REFERENCES}

1. C.L. Mavis, A Description and Assessment of Heliostat Technology, SAND87-8025 Sandia National Laboratories, California, 1987.

2. Sandia National Laboratories California, Prototype/Second Generation Heliostat Evaluation and Reconmendations, Executive Suminary, 1978.

3. Martin Marietta Corporation, Second Generation Heliostat Optimization Studies, SAND82-8175, Sandia National Laboratories, 1982.

4. McDonnell Douglas Astronautics Company, Optimization of the Second Generation Heliostat and Specification, SAND82-8181, Sandia National Laboratories, 1982.

5. Personal communication from D. Gorman Advanced Thermal Systems, Inc., to J.W. Strachan and R.M. Houser, June-August, 1992.

6. Winsmith, Development of a Low-Cost Drive Tracking Mechanism for Solar-Heliostats or PV Array's, contract report for Sandia National Laboratories, Document No. 9()-5753, 1989.

7. Heliostat Development Division, Second Generation Heliostat Evaluation Executive Summary, SAND81-8(133, Sandia National I aboratories, 1982.

8. PG\&E, RI)\&I) Solar Central Receiver Techology Advancentent for Electric Utility Applications, Phase 1 Topical Report, Vol. 1, Report \#()()7.2-88.2, 1988.

9. J. W. Strachan, Revisiting the BCS, a Measurement System for Characterizing the Optics of Solar Collectors, ISA/93 Conference Proceedings, Albuquerque, NM, 1993.

10. R. B. Pettit, I. M. Freese, A. R. Mahoney, "The Development of a Portable Specular Reflectometer for Monitoring Solar Mirror Materials, Optical Materials and Process Technology for Energy Efficiency and Solar Applications," International Society for Optical Engineering, Vol. 428, pp. 125$134,1983$.

11. F. Biggs and C.N. Vittitoe, The HELIOS Model for the Optical Behavior of Reflecting Solar Concentrators, SAND76-(1)347, Sandia National Iaboratories, 1979.

12. I.W. Grossman, Static Load Testing of a Heliostat Drive, SAND9()-2624, Sandia National Laboratories, 1991.

13. Correspondence dated February 27, 1989, from Werner H. Heller, Peerless-Winsmith, Inc. to J.W. Grossman, Sandia National Laboratories, Albuquerque, included a three-page repon, "Evaluation of Failed Azimuth Drive Unit."

14. Bevington, P.R., Data Reduction and Error Analysis for the Physical Sciences, McGraw-Hill Book Company, New York, NY, 196.5, p. 61. 


\section{APPENDICES}

\section{Appendix A: ATS All-Day Beam Quality Test Data}

Table 10 contains the original measured lest parameters obtained during the all-day beam quality test of the ATS heliostat on August 26, 1992. The Beam Characterization System was employed in the tests, and the approximate measurement uncertainty (average measurement error) of that system is 6 to $8 \%$ for the total beam power and peak flux measures, $2 \%$ for the beam diameter and for the relative flux distribution, and $1 \%$ for the normal incidence pyroheliometer (NIP') measure.

Table 10. ATS All-Day Beam Quality Test Results

Test 1)ay: August 26, 1991

\begin{tabular}{|c|c|c|c|c|c|c|}
\hline \multirow[b]{2}{*}{ 'Tïne } & \multirow{2}{*}{$\begin{array}{c}\text { Hr from } \\
\text { Solial } \mathrm{N}(\mathrm{s}) \mathrm{n}\end{array}$} & \multirow{2}{*}{$\begin{array}{c}\text { NII } \\
\left(k W / m^{2}\right)\end{array}$} & \multicolumn{2}{|c|}{ Total Beam Pwr (kW): } & \multirow{2}{*}{$\begin{array}{c}\text { Efliective } \\
\text { Beam I)ia. } \\
\text { (I!) }\end{array}$} & \multirow{2}{*}{$\begin{array}{c}\text { Peak } \\
\text { Hlux } \\
\left(\mathrm{kW} / \mathrm{m}^{2}\right)\end{array}$} \\
\hline & & & Calc. & Meas'd. & & \\
\hline (1) $8:(12$ a.m. & -5.10 & 0.645 & 01.9 & 61.7 & 0.78 & 3.11 \\
\hline (1)8:3() al.mI. & -4.63 & 0.723 & 71.2 & 71.1 & 6.22 & 4.59 \\
\hline (1):(1) al.m. & -4.10 & 0.784 & 81.2 & 81.5 & 5.60 & 6.46 \\
\hline (1):30) a.m. & -3.58 & 0.828 & 80.9 & 87.9 & 5.27 & 8.19 \\
\hline l():()] a.m. & -3.08 & ().8.52 & 90.9 & $\mathscr{9} 2.4$ & 4.84 & 10.60 \\
\hline $1(1: 3()$ a.m. & $-2 .(0)$ & 0.881 & 95.9 & $1(1) 1.1$ & 4.49 & 13.87 \\
\hline $11:(x)$ a.m. & -2.10 & $(1.9(1) 2$ & 99.3 & $1(1) 8.8$ & 4.16 & 17.36 \\
\hline $11: 28$ al.m. & -1.67 & $(1.910$ & 1011.4 & $10(1) .6$ & 3.99 & 18.49 \\
\hline 12:()() p.m. & -1.10 & 0.928 & $1(1) 3.4$ & 106.8 & 3.8 .5 & $2(1) .(1) 4$ \\
\hline 12:3(1) p.m. & -0.63 & 0.937 & $1(14.4$ & 111.3 & 3.89 & 21.112 \\
\hline 1:(k) p.m. & $-(1) .10$ & (1.9.36 & $1(1) 4.3$ & 109.3 & 3.85 & 20.59 \\
\hline 2:(18 p.III. & 1.013 & $(0.929$ & $11) 2.3$ & 106.3 & 4.3() & 16.81 \\
\hline $2: 4.3$ p.III. & 1.62 & $(1.906$ & 98.6 & 103.7 & 4.6 .3 & 14.211 \\
\hline $3:(19$ p.m. & 2.117 & (1.910 & 97.9 & 99.4 & 4.93 & 11.36 \\
\hline $3: 39$ p.m. & 2.5 .5 & $(0.891$ & 93.5 & 94.4 & 5.35 & 9.119 \\
\hline $4:(19$ p.III. & 3.117 & $(1) .870$ & 80.0 & 93.8 & 5.69 & 7.25 \\
\hline $5: 11$ p.m. & 4.118 & 0.792 & 73.9 & 72.2 & 0.111 & 4.52 \\
\hline $5: 41$ p.m. & 4.62 & 0.720 & 64.6 & 66.7 & 7.21 & 3.24 \\
\hline 6:(1) p.m. & 5.07 & 0.479 & 41.2 & $4(1) .7$ & 7.54 & 1.79 \\
\hline $6: 39$ p.m. & 5.55 & 0.53 .3 & 44.5 & 45.7 & 7.95 & 1.81 \\
\hline
\end{tabular}




\section{Appendix B: SPECO Aii-Day Beam Quality Test Data}

Table 11 contains the original measured test parameters obtained during the all-day beam quality test of the SPECO heliostat on August 27, 199'\%. The Beam Characterization System was employed in the tests and the approximate measurement uncertainty (average measurement error) of that system is 6 to $8 \%$ for the total beam power and peak flux measures, $2 \%$ for the beam diameter and for the relative flux distribution, and $1 \%$ for the normal incidence pyroheliometer (NIP) measure.

\begin{tabular}{|c|c|c|c|c|c|c|}
\hline \multicolumn{7}{|c|}{$\begin{array}{c}\text { Table 11. SPECO All-Day Beam Quality Test Results } \\
\text { Test Day: August 27, 1991 }\end{array}$} \\
\hline \multirow[b]{2}{*}{ Tim: } & \multirow[b]{2}{*}{ Solar Noon } & \multirow{2}{*}{$\begin{array}{c}\mathrm{NiP} \\
(\mathrm{kW} / \mathrm{sq} \mathrm{m})\end{array}$} & \multicolumn{2}{|c|}{ Tot al Bcam Pur (kW): } & \multirow{2}{*}{$\begin{array}{c}\text { Erfective } \\
\text { Beam Dia. } \\
(\mathrm{m})\end{array}$} & \multirow{2}{*}{$\begin{array}{c}\text { Peak } \\
\text { Flux } \\
\left(\mathrm{kW} / \mathrm{m}^{2}\right)\end{array}$} \\
\hline & & & Calc. & Mcas'd. & & \\
\hline $8:(1) .3$ & $-5 .(1) 8$ & 0.674 & 69.4 & 58.3 & 9.38 & 1.82 \\
\hline $8: 3(1)$ & -4.6 .3 & 0.748 & 79.1 & 76.9 & 9.18 & 2.54 \\
\hline $9:(1)$ & $-4.1:$ & 0.811 & 89.2 & 91.2 & 8.89 & 3.25 \\
\hline $9: 3(1)$ & -3.6 .3 & 0.856 & 96.9 & 95.8 & 8.33 & 3.75 \\
\hline $1(0: 1) 11$ & -3.12 & 0.888 & $1(14.0$ & 102.2 & 7.72 & 4.60 \\
\hline $10: 42$ & -2.43 & 0.913 & 109.3 & 112.4 & 6.85 & 6.93 \\
\hline $11:(1) 3$ & -2.118 & $(j .929$ & 118.1 & 111.2 & 6.35 & 8.14 \\
\hline $11: 30$ & -1.63 & 0.938 & 121.5 & 116.0 & 5.76 & 10.26 \\
\hline $12:(14$ & $-1 .(17$ & 0.941 & 12.5 & 115.9 & 5.22 & 12.52 \\
\hline $12: 30$ & $-(1) .63$ & 0.944 & 125.8 & 112.1 & 4.79 & 14.3() \\
\hline $13:(1)$ & $-(1) .13$ & 0.945 & 125.3 & 119.9 & 4.75 & 15.92 \\
\hline $13: 3(1)$ & 0.37 & $(1.949$ & 127.3 & 122.7 & 4.7() & 16.72 \\
\hline $14:()(0)$ & 0.87 & 0.946 & 126.8 & 116.3 & 4.86 & $15 .(1) 3$ \\
\hline $14: 30$ & 1.37 & 0.9 .34 & 123.9 & 114.8 & 5.40 & 11.93 \\
\hline $15:(x)$ & 1.87 & 0.912 & 120.9 & 112.3 & 5.90 & 9.91 \\
\hline $15: 30$ & 2.37 & 0.911 & 119.4 & 116.6 & 6.55 & 7.96 \\
\hline $16:(1) 1$ & 2.88 & 0.897 & 115.1 & 110.7 & 7.16 & 6.23 \\
\hline $16: 30$ & 3.37 & 0.894 & 112.5 & 105.9 & 7.61 & 5.25 \\
\hline $17: 01$ & 3.88 & 0.842 & 10.3 .4 & 104.5 & 8.114 & 4.61 \\
\hline $17: 31$ & 4.37 & 0.8 & 9.5 .7 & 96.7 & 8.29 & $4 .(1)$ \\
\hline $18:(1)$ & 4.87 & 0.736 & $8 \therefore 6$ & 75.2 & 8.56 & 2.79 \\
\hline $18: 3(1)$ & 5.37 & 0.599 & 67.3 & 63.0 & 8.85 & 2.12 \\
\hline $18: 54$ & 5.77 & 0.435 & 47.3 & 40.1 & 8.71 & 1.34 \\
\hline
\end{tabular}




\section{Appendix C: Normalization Procedure for Comparison of Beam Quality Test Results}

Figures 12 and 13 of this report provide a comparison of the all-day beam quality performance of the two heliostats. The plots are based on the original test data, but the data has been normalized and otherwise treated in order to eliminate performance differences due to differences in insolation and heliostat-to-sun geometry at the time of each separate measurement as well as the difference in collection area of the two heliostats.

As stated in the text of the report, the intent of these normalizations was to preserve the verisimilitude of the data by retaining the effect on power collection of the reduced insolation, the higher air mass, and the poorer sun-heliostat-target geometry in the early morning and late afternoon while eliminating the effects of different heliostat collection areas, insolation levels, and heliostat-to-sun orientations.

The total beam power values plotted in Fig. 12 adjusted the original power values of each heliostat as follows:

$\mathrm{PN}=(\mathrm{PH} / \mathrm{AH})(\mathrm{NIPAVG} / \mathrm{NIPH})(\mathrm{COSAVG} / \mathrm{COSH})$.

In Eq. (1), $P_{N}$ is the normalized power (the value to be plotted in the comparison chart), $P_{I I}$ is the actual measured power, and $\mathrm{A}_{\mathrm{H}}$ is the collector area. $\mathrm{NIP}_{\mathrm{AVG}}$ and $\mathrm{NIP}_{\mathrm{H}}$ are, respectively, the insolation at the time of the BCS measurement and the average insolation for BCS measurements made during that (10)-15 minute) interval of the day. The term COS refers to the cosine loss, which is merely the cosine of the angle between the normal to the heliostat surface and the sun vector. $\operatorname{COS}_{\mathrm{II}}$ is the actual cosine loss for the heliostat in question at the time of the BCS measurement, while $\operatorname{COS}_{\mathrm{AVG}}$ is the average of the cosine losses for those measurement made during that interval of the day.

The peak flux measurements for the two heliostats were adjusted in terms of input insolation by normalizing them to an average insolation value for that time of the day:

$\mathrm{PF}_{\mathrm{N}}=\mathrm{PF}_{\mathrm{H}}\left(\mathrm{NIP}_{\mathrm{AVG}} / \mathrm{NIP}_{\mathrm{H}}\right)$

$\mathrm{PF}_{\mathrm{H}}$ and $\mathrm{PF}_{\mathrm{N}}$ are the heliostat's measured and normalized peak flux values, respectively, and NIP $\mathrm{AVG}$ and NIP ${ }_{H}$ have the same meaning as in Eq. (1).

In order to eliminate the performance difference because of differences in the reflectivity of the ATS and SPEC() mirror modules, the beam quality data was normalized in terms of mirror reflectivity. The resulting data are compared in a plot in Fig. 14; the beam power data in that plot were normalized as follows:

$P_{i j}=P_{i v} / R_{i i}$ 
In Eq. (3) $P_{N}$ ' is the total beam power normalized for reflectivity, while $P_{N}$ is the beam power previously normalized as described in Eq. (1). $R_{H}$ is the reflectivity of the heliostat in question, while $P_{N}$ is the beam power further normalized to the ATS reflectivity. The reflectivity of the ATS measured at the time of this test is $R_{\text {ATS }}$. That of the SPECO is $R_{\text {SPECO. }}$ 


\section{Appendix D: Analysis of Measurement Error in the Beam Characterization System}

The individual elements of the BCS flux map array may be in error either in terms of the flux density value or the physical dimension and/or position of the pixel. Pixel geometry (pixel height and width) in the BCS image is easily corrected for the lengthening or foreshortening due to the non-normal flux incident angle on the target or the capture angle of the camera relative to the same. But based on experience, the use of highquality lenses ensures that any physical distortion of the image due to the lens assembly is small enough to be ignored.

Given the BCS components currently in use, the resolution of the flux measurement is 1 part in 256 (8 computer bits) or about $0.5 \%$ of the full-scale intensity level in the image. The system's geometric resolution (the size and number of picture elements) is dependent on the camera sensor and the digitizer, and, of course, the distance from the camera to the target. The picture array size for common digital imaging systems is in the range from a $250 \times 250$ to a $10(0) \times 10(0)$ array. The uncertainties associated with the flux density measurement are not small enough to ignore, and their analysis is the subject of this section.

Consider a small area of the flux target corresponding exactly to a single picture element of the BCS image. Let $\mathbf{F}$ be the average flux density over that area; we'll also reier to the "flux bundle" from the collector that is incident on that area at the moment of the measurement. The aim of the analysis is to establish the uncertainty associated with the BCS measure of $\mathbf{F}$.

$\mathbf{F}$ is processed as an input signal hy the measurement system, and the output (from the image digitizer) is a pixel level which we'll call $\mathbf{P}$. In a manner of speaking, during its passage through the $B C S, F$ is transformed by each successive element: the target, the neutral density (ND) filters, the lens assembly, the camera sensor, and finally, the digitizer (frame grabber). The validity of the measurement process requires that each successive transformation be linear and constant over both the full flux range and over the entire target. Thus, the collector hux reflected from a pixel-sized area on the target toward the camera must be proportional to the collector flux incident on that area. Let us call this constant (output/input) ratio $\mathbf{k}_{\mathrm{T}}$ ( $\mathrm{T}$ for target!); $\sigma_{k_{\mathrm{T}}}$ is the standard deviation (for all the pixels in that image) of $\mathbf{k}_{\mathrm{T}}$, and is the expected error or deviation of the ratio from pixel to pixel. We define similar terms for each succeeding "in-line" element in the measurement: $\mathbf{k}_{\mathrm{NI}}$ for the ND filters, $\mathbf{k}_{\mathrm{L}}$ for the lens assembly, $\mathbf{k}_{\mathrm{C}}$ for the camera sensor, and $\mathbf{k}_{\mathrm{D}}$ for the image digitizer. The error associated with each is likewise its standard deviation of the given $\mathbf{k}$ term for the population of pixels in the image. We can employ these terms to express the relationship between the flux density, F, and the pixel level, $\mathbf{P}$ :

$\mathrm{P}=\mathrm{k}_{\mathrm{D}} \cdot \mathrm{k}_{(} \cdot \mathrm{k}_{\mathrm{L}} \cdot \mathrm{k}_{\mathrm{ND}} \cdot \mathrm{k}_{\mathrm{T}} \cdot \mathrm{F}$. 
And, assuming that the errors in each of the $\mathbf{k}$ terms are independent, we can express the error [14] associated with $\mathbf{P}$ as

$\left(\sigma_{\mathrm{P}} / \mathrm{P}\right)^{2}=\left(\sigma_{\mathrm{k}_{\mathrm{D}}} / \mathrm{k}_{\mathrm{D}}\right)^{2}+\left(\sigma_{\mathrm{k}_{\mathrm{C}}} / \mathrm{k}_{\mathrm{C}}\right)^{2}+\left(\sigma_{\mathrm{k}_{\mathrm{L}}} / \mathrm{k}_{\mathrm{L}}\right)^{2}+\left(\sigma_{\mathrm{k}_{\mathrm{ND}}} / \mathrm{k}_{\mathrm{ND}}\right)^{2}+\left(\sigma_{\mathrm{k}_{\mathrm{T}}} / \mathrm{k}_{\mathrm{T}}\right)^{2}$

In this expression for measurement uncertainty, the ratio $\left(\sigma_{\mathrm{P}} / \mathrm{P}\right)$ gives the expected error as a percent (or fraction) of the full-scale value of $\mathbf{P}$.

Determining pixel intensity error by this means requires information about the error of each of the BCS components. In practice, an alternative, experimental measure of relative pixel intensity error is possible by evaluating the uniformity of a BCS image of the flux target while it is illuminated uniformly. If the target is uniformly illuminated, any non-uniformities in the resulting digitized image are a measure of system measurement error.

The pixel-level-to-flux-density conversion factor for the BCS image is the ratio of the flux gauge measurement $\left(\mathbf{F}_{\mathrm{FG}}\right.$ )and the pixel level, $\mathbf{P}_{\mathrm{FG}}$, at the location of the flux gauge

$\mathrm{F}=\left(\mathrm{F}_{\mathrm{FG}} / \mathrm{P}_{\mathrm{FG}}\right) \cdot \mathrm{P}$

These two values also introduce error into the measurement. Since these errors are independent of one another, the uncertainty in $\mathbf{F}$ can be expressed in terms of $\mathbf{F}_{\mathrm{FG}}, \mathbf{P}_{\mathrm{IG}}$, and $\mathbf{P}$ :

$\left(\sigma_{\mathrm{F}} / \mathrm{F}\right)^{2}=\left(\sigma_{\mathrm{F}_{\mathrm{R}}} / \mathrm{F}_{\mathrm{FG}}\right)^{2}+\left(\sigma_{\mathrm{P}_{\mathrm{P}}} / \mathrm{P}_{\mathrm{FG}}\right)^{2}+\left(\sigma_{\mathrm{P}} / \mathrm{P}\right)^{2}$

The accuracies of the BCS flux measurement are listed in Table 12. The estimated error for individual heliostat measurements is $10 \%$ (of the peak flux level in the llux map), and for groups of heliostats as well as for point-focus collectors it is $6 \%$. In each case, the flux gauge is the source of largest error and lies with the large uncertainty associated with the calibration of the gauges. The calibration uncertainty is greatest for the gauges used for single heliostat measurements and is the focus of attention in current efforts to improve the BCS. The larger error associated with estimating the level of the flux gauge pixel for the dish concentrator BCS is due to the fact that because of the small size of the collector beam the flux gauge produces a larger perturbation in the image. In addition, the flux gradient across the gauge is also usually lairly steep, which increases the uncertainty of the flux measurement itself. 


\begin{tabular}{|l|l|l|l|}
\hline \multicolumn{3}{|c|}{ Table 12. Estimates of BCS Error for Heliostats and Dish Concentrators Measurements } \\
\hline Source of Measurement Uncertainty & \multicolumn{3}{|c|}{ BCS System and Component Measurement Uncertainty } \\
\hline & Dish Concentrators & Single Heliostats: & Heliostat Groups: \\
\hline Pixel Level, $\left(\sigma_{\mathrm{P}} / \mathrm{P}\right)$ & $<1 \%$ & $2 \%$ & $1 \%$ \\
\hline Flux gauge, $\left(\sigma_{\mathrm{F}:} / \mathrm{F}_{\mathrm{FG}}\right)$ & $5 \%$ & $10 \%$ & $5 \%$ \\
\hline $\begin{array}{l}\text { Estimate of Pixel Level at Flux Gauge: } \\
\left(\sigma_{\mathrm{P}_{\mathrm{R}}} / \mathrm{P}_{\mathrm{FG}}\right)\end{array}$ & $3 \%$ & $1 \%$ & $1 \%$ \\
\hline Overall Uncertainty, $\left(\sigma_{\mathrm{F}} / \mathrm{F}\right)$ & $6 \%$ & $10 \%$ & $6 \%$ \\
\hline
\end{tabular}




\section{Appendix E: Determining the Solar Average Specular Reflectivity of a Collector Mirror}

The Device \& Services (D \& S) Portable Specular Reflectometer employs 660-nm wavelength light as its light source for measurements, so collector mirror measurements made with the device must be adjusted to obtain an estimate of the mirror's reflectivity over the solar spectrum.

To do this requires prior knowledge of the following:

1. The solar average total hemispherical reflectivity, $R_{2 \pi, S . A \text {. }}$ of the mirror material which is its average reflectivity over the 3()() - to 25()() -nm range of the spectrum, a range containing more than $90 \%$ of the available energy. This is determined from a laboratory test or from the literature.

2. The hemispherical reflectivity of the same sample for 66()$-\mathrm{nm}$ light, $\mathrm{R}_{2 \pi, 660 \mathrm{~nm}}$.

These two measures provide a means of determining the difference between the mirror sample's reflectivity over the solar spectrum to its reflectivity at 66() $\mathrm{nm}$.

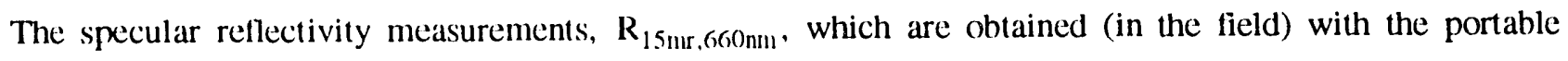
D\&S reflectometer and using a 15-mr aperture are then adjusted as follows to obtain the solar averaged specular ( $15 \mathrm{mr}$ aperture) reflectivity, $\mathrm{R}_{15 \mathrm{mur} . \mathrm{S.A} \text {. }}$ of the mirror module:

$R_{15 m, S . A .}=R_{2 p, S . A .}-\left(R_{2 p, 660 \mathrm{~mm}}-R_{15 \mathrm{mI}, 660 \mathrm{~nm}}\right)$. 


\section{DISTRIBUTION:}

U.S. Department of Energy (5)

Forrestal Building

Code CE-132

1000 Independence Avenue, SW

Washington, DC 20585

Attn: G. Burch

S. Gronich

U.S. Department of Energy (2)

Forrestal Building

Code CE-13

1000 Independence Avenue, SW

Washington, DC 20585

Attn: R. Annan

U.S. Department of Energy (2)

Albuquerque Operations Office

P.O. Box 5400

Albuquerque, NM 87115

Attn: G. Tennyson

N. Lackey

U.S. Department of Energy

San Francisco Operations Office 1333 Broadway

Oakland, CA 94612

Attn: R. Hughey

Acurex Corporation (2)

555 Clyde Avenue

Mountain View, CA 94039

Attn: J. Schaefer

H. Dehne

Advanced Thermal Systems

7600 East Arapahoe

Suite 319

Englewood, CO 80112

Attn: D. Gorman

Agua y Energia Electrica

Sociedad del Estado

Attn: Grupo - Fuentes Alternas

Gabato 3713

1826 Remedios de Escalada

Buenos Aires, ARGENTINA
Allegheny Ludlum Steel (2)

Market and Product Development

Alabama and Pacific Avenues

Brackenridge, PA 15014

Attn: J.M. Hunt

J.P. Ziemianski

Allegheny Ludlum Steel

80 Valley St.

Wallingford, CT 06492

Attn: J.J. Halpin

Analysis Review \& Critique

6503 81st St.

Cabin John, MD 20818

Attn: C. LaPorta

Arizona Public Service Company

P.O. Box 53999

Phoenix, AZ 85072

Attn: J. McGuirk

Arizona Solar Energy Office

Dept. of Commerce

3800 N. Central

Phoenix, AZ 85012

Attn: F. Mancini

Australian National University

Department of Engineering Physics

P.O. Box 4

Canberra ACT 2600 AUSTRALIA

Attn: S. Kaneff

Barber-Nichols Engineering

6325 West 55th Avenue

Arvada, CO 80002

Attn: R. Barber 
Battelle Pacific Northwest Laboratory (2) P.O. Box 999

Richland, WA 99352

Attn: D. Brown

BDM Coporation

1801 Randolph Road, S.E.

Albuquerque, NM 87106

Attn: W. Schwinkendorf

Bechtel National, Inc. (4)

50 Beale Street

50/15 D8

P.O. Box 3965

San Francisco, CA 94106

Attn:

P. DeLaquil

S. Nickovich

B. Kelly

J. Egan

Bomin Solar

Industriestr. 8

D-7850 Lorrach

GERMANY

Attn: Dr. Hans Jurgen Kleinwachter

Black \& Veatch Consulting Engineers (2)

P.O. Box 8405

Kansas City, MO 64114

Attn: J. C. Grosskreutz

Tom Brumleve

1512 Northgate Road

Walnut Creek, CA 94598

California Energy Commission

1516 Ninth Street, M-S 43

Sacramento, CA 95814

Attn: A. Jenkins

California Polytechnic University

Dept. of Mechanical Engineering

3801 West Temple Avenue

Pomona, CA 91768

Attn: W. Stine
California Public Utilities Com.

Resource Branch, Room 5198

455 Golden Gate Avenue

San Francisco, CA 94102

Attn: T. Thompson

Central and Southwest Services

Mail Stop 7RES

1616 Woodall Rogers Freeway

Dallas, TX 75202

Attn: E.L. Gastineau

Centro Investigaciones Energeticas (4)

Medioambientales y Technologicas

Instituto de Energias Renovables

Avda. Complutense, 22

28040 Madrid, SPAIN

Attn: M. Macias M. Romero

E. Conejero J.M. Figarola

Clever Fellows

Innovation Consortium, Inc.

R.D. 1, Box 410, River Road

Melrose, NY 12121

Attn: J. A. Corey, P.E.

Cummins Power Generation (2)

MC 60125

P.O. Box 3005

Columbus, IN 47202-3005

Attn: R. Kubo

Cummins Power Generation South

150 Tannehill Drive

Abilene, TX 79602

Attn: M. McGlaun

Dan Ka Products, Inc.

3905 South Mariposa

Englewood, CO 80110

Attn: D. Sallis

Dynatherm Corporation

1 Beaver Court

P.O. Box 398

Cockeysville, MD 21030

Attn: Dr. W. Bienert

D. Wolf 


\author{
DLR \\ Pfaffenwaldring 38-40 \\ 7000 Stuttgart 80 GERMANY \\ Attn: R. Buck

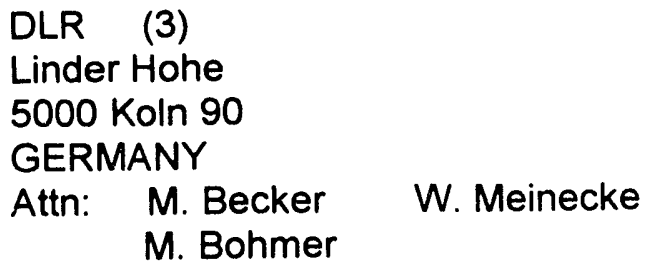 \\ Electric Power Research Institute \\ P.O. Box 10412 \\ Palo Alto, CA 94303 \\ Attn: J. Schaeffer \\ El Paso Electric Company \\ $303 \mathrm{~N}$. Oregon, 10th Floor \\ P.O. Box 982 \\ El Paso, TX 79960 \\ Attn: D. Gutierrez \\ Energy Research Centre (2) \\ R.S. Phy. Sc. \\ Australian National University \\ Canberra ACT 2601 \\ AUSTRALIA \\ Attn: K. Inall \\ Energy Technology Engr. Center \\ Rockwell International Corp. \\ P.O. Box 1449 \\ Canoga Park, CA 91304 \\ Attn: W. Bigelow \\ Engineering Perspectives \\ 20 19th Ave. \\ San Francisco, CA 94121 \\ Attn: J. Doyle \\ ENTECH, Inc. \\ P.O. Box 612246 \\ DFW Airport, TX 75261 \\ Attn: R. Walters
}

Flachglas Solartechnik GmbH

Muhlengasse 7

D-5000 Koln 1

FEDERAL REPUBLIC OF GERMANY

Attn: J. Benemann

Flachglas Solartechnik GmbH (2)

Theodor-Heliss-Ring 1

5000 Koln 1

Germany

Attn: Dr. M. Geyer

I. Susemihl

Florida Solar Energy Center

300 State Road, Suite 401

Cape Canaveral, FL 32920

Attn: Library

Ford Aerospace

Ford Road

Newport Beach, CA 92663

Attn: R. Babbe

Foster Wheeler Solar Development

Corporation (2)

12 Peach Tree Hill Road

Livingston, NJ 07039

Attn: M. Garber

R. Zoschak

Garrett Turbine Engine Co.

111 South 34th Street

P.O. Box 5217

Phoenix, AZ 85010

Attn: E. Strain

LUZ International (2)

924 Westwood Blvd.

Los Angeles, CA 90024

Attn: D. Kearney

Georgia Institute of Technology

GTRI/EMSL Solar Site

Atlanta, GA 30332

Attn: T. Brown 
Georgia Power (2)

7 Solar Circle

Shenandoah, GA 30265

Attn: W. King

Harris Corporation (2)

Government Aerospace Systems Division

P.O. Box 9400

Melbourne, FL 32902

Attn: K. Schumacher

Industrial Solar Technologies (4)

5775 West 52nd Avenue

Denver, CO 80212

Attn:

R. Gee

K. May

Institute of Gas Technology

34245 State Street

Chicago, IL 60616

Attn: Library

Interatom GmbH (2)

P.O. Box D-5060 Bergisch-Gladbach

FEDERAL REPUBL!C OF GERMANY

Attn: M. Kiera

Jet Propulsion Laboratory

4800 Oak Grove Drive

Pasadena, CA 91109

Attn: M. Alper

Lawrence Berkeley Laboratory

MS 90-2024

One Cyclotron Road

Berkeley, CA 94720

Attn: A. Hunt

Leo Gutierrez

434 School Street

Livermore, CA 94550
Los Angeles Dept. of Water and Power

Alternate Energy Systems

111 North Hope Street, Room 661A

Los Angeles, CA 90012

Attn: B. Engels

McDonnell-Douglas

Astronautics Company (3)

5301 Bolsa Avenue

Huntington Beach, CA 92647

Attn: R. L. Gervais

D. Steinmeyer

J. Rogan

Mechanical Technology, Inc. (2)

968 Albany Shaker Road

Latham, NY 12110

Attn: G. Dochat

J. Wagner

Meridian Corporation

4300 King Street, Suite 400

Alexandria, VA 22302-1508

Attn: D. Kumar

NASA Lewis Research Center (4)

21000 Brook Park Road

Cleveland, $\mathrm{OH} 44135$

Attn: R. Shaltens

J. Schrieber

National Renewable

Energy Laboratory

1617 Cole Boulevard

Golden, CO 80401

Attn: T. Williams

L. M. Murphy

G. Jorgensen

T. Wendelin

A. Lewandowski

M. Bohn

Nevada Power Co.

P.O. Box 230

Las Vegas, NV 89151

Attn: Mark Shank

New Mexico Solar Energy Institute

New Mexico State University

Box 3SOL

Las Cruces, NM 88003 
Northern Research and

Engineering Corp.

39 Olympia Avenue

Woburn, MA 01801-2073

Attn: J. Kesseli

Pacific Gas and Electric Company (2)

3400 Crow Canyon Road

San Ramon, CA 94526

Attn: G. Braun

J. Iannucci

Power Kinetics, Inc. (2)

415 River Street

Troy, NY 12180-2822

Attn: W. E. Rogers

Renewable Energy Institute 1001 Connecticut Ave. NW

Suite 719

Washington, DC 20036

Attn: K. Porter

Rocketdyne Division

6633 Canoga Park Ave.

Canoga Park, CA 91304

Attn: W. Marlatt

Sacramento Municipal Utility District

Generation Systems Planning

Power Systems Department

6201 S Street

P.O. Box 15830

Sacramento, CA 96852-1830

Attn: R.P. Wichert, P.E.

San Diego Gas and Electric Company

P.O. Box 1831

San Diego, CA 92112

Attn: R. Figueroa

Schlaich, Bergermann \& Partner

Hohenzollernstr. 1

D - 7000 Stuttgart 1 GERMANY

Attn: W. Schiel
Science Applications

International Corporation

10343 Roselle Street, Suite G

San Diego, CA 92121

Attn: K. Beninga

Science Applications

International Corporation

Mail Stop 32

10260 Campus Point Court

San Diego, CA 92121

Attn: B. Butler

Sci-Tech International

Advanced Alternative Energy Solutions

5673 W. Las Positas Blvd. Suite 205

P.O. Box 5246

Pleasanton, CA 84566

Attn: U. Ortabasi

Solar Energy Industries Assoc. (2)

777 North Capitol St. NE, Suite 805

Washington, DC 20002

Attn: S. Sklar

K. Sheinkopf

Solar Kinetics, Inc. (2)

P.O. Box 540636

Dallas, TX 75354-0636

Attn: J.A. Hutchison

P. Schertz

Solar Power Engineering Company (10)

P.O. Box 91

Morrison, CO 80465

Attn: $\quad H$. Wroton

D. Bielenberg (9)

Solar Steam

P.O. Box 32

Fox Island, WA 98333

Attn: D. Wood

South Coast AQMD

9150 Flair Drive

El Monte, CA 91731

Attn: L. Watkins 
Southern California Edison (3)

P.O. Box 800

Rosemead, CA 91770

Attn: P. Skvarna

SRS Technologies

990 Explorer Blvd. NW

Huntsville, AL 35806

Attn: R. Bradford

Stearns Catalytic Corporation

P.O. Box 5888

Denver, CO 80217

Attn: T.E. Olson

Stirling Machine World

1823 Hummingbird Court

West Richland, WA 99352-9542

Attn: B. Ross

Stirling Technology Company (2)

2952 George Washington Way

Richland, WA 99352

Attn: M.A. White

Stirling Thermal Motors (2)

275 Metty Drive

Ann Arbor, MI 48103

Attn: L. Johansson

Stone and Webster Engineering Corp.

P.O. Box 1214

Boston, MA 02107

Attn: R.W. Kuhr

Sulzer Bros, Ltd.

New Technologies

$\mathrm{CH}-8401$ Winterthur

SWITZERLAND

Attn: H. Fricker, Manager
Sunpower, Inc.

6 Byard Street

Athens, $\mathrm{OH} 45701$

Attn: W. Beale

Thermacore, Inc. (2)

780 Eden Road

Lancaster, PA 17601

Attn: D. Ernst

Tom Tracey

6922 South Adams Way

Littleton, CO 80122

United Solar Tech, Inc.

3434 Martin Way

Olympia, WA 98506

Attn: R. Kelley

University of Arizona

Engineering Experimental Station

Harvil Bldg., Room 151-D

Tucson, AZ 85721

Attn: D. Osborne

University of Chicago

Enrico Fermi Institute

5640 Ellis Avenue

Chicago, IL 60637

Attn: J. O'Gallagher

University of Houston

Solar Energy Laboratory

4800 Calhoun

Houston, TX 77704

Attn: L. Vant-Hull

J. Richardson

University of Minnesota (2)

Dept. of Mechanical Engineering

111 Church St., SE

Minneapolis, MN 55455

Attn: E. A. Fletcher

T. Simmon 
University of New Mexico (2)

Dept. of Mechanical Engineering

Albuquerque, NM 87131

Attn: M. W. Wilden

W. A. Gross

University of Nevada at Las Vegas

Mechanical Engineering Dept.

Las Vegas, NV 89154

Attn: B. Boehm

WG Associates

6607 Stonebrook Circle

Dallas, TX 75240

Attn: V. Goldberg

SANDIA INTERNAL:

$\begin{array}{ll}1513 & \text { D.R. Adkins } \\ 1708 & \text { R.E. Loehman } \\ 1846 & \text { D.H. Doughty } \\ 1846 & \text { C.S. Ashley } \\ 2402 & \text { J.L. Ledman } \\ 2476 & \text { F.P. Gerstle } \\ 2476 & \text { S.T. Reed } \\ 6200 & \text { D.L. Hartley } \\ 6200 & \text { B.W. Marshall } \\ 6201 & \text { P.C. Klimas } \\ 6202 & \text { G.L. Jones } \\ 6213 & \text { A.R. Mahoney } \\ 6215 & \text { C.P. Cameron } \\ 6215 & \text { W.W. Erdman } \\ 6215 & \text { R.M. Edgar } \\ 6215 & \text { R.M. Houser (10) } \\ 6215 & \text { J.W. Strachan (20) } \\ 6215 & \text { L. Yellowhorse } \\ 6215 & \text { Library (5) }\end{array}$

Eric Weber

302 Caribbean Lane

Phoenix, AZ 85022

David White

3915 Frontier Lane

Dallas, TX 95214

3M-Energy Control Products (2)

207-1W 3M Center

St. Paul, MN 55144

Attn: R. Dahlen 

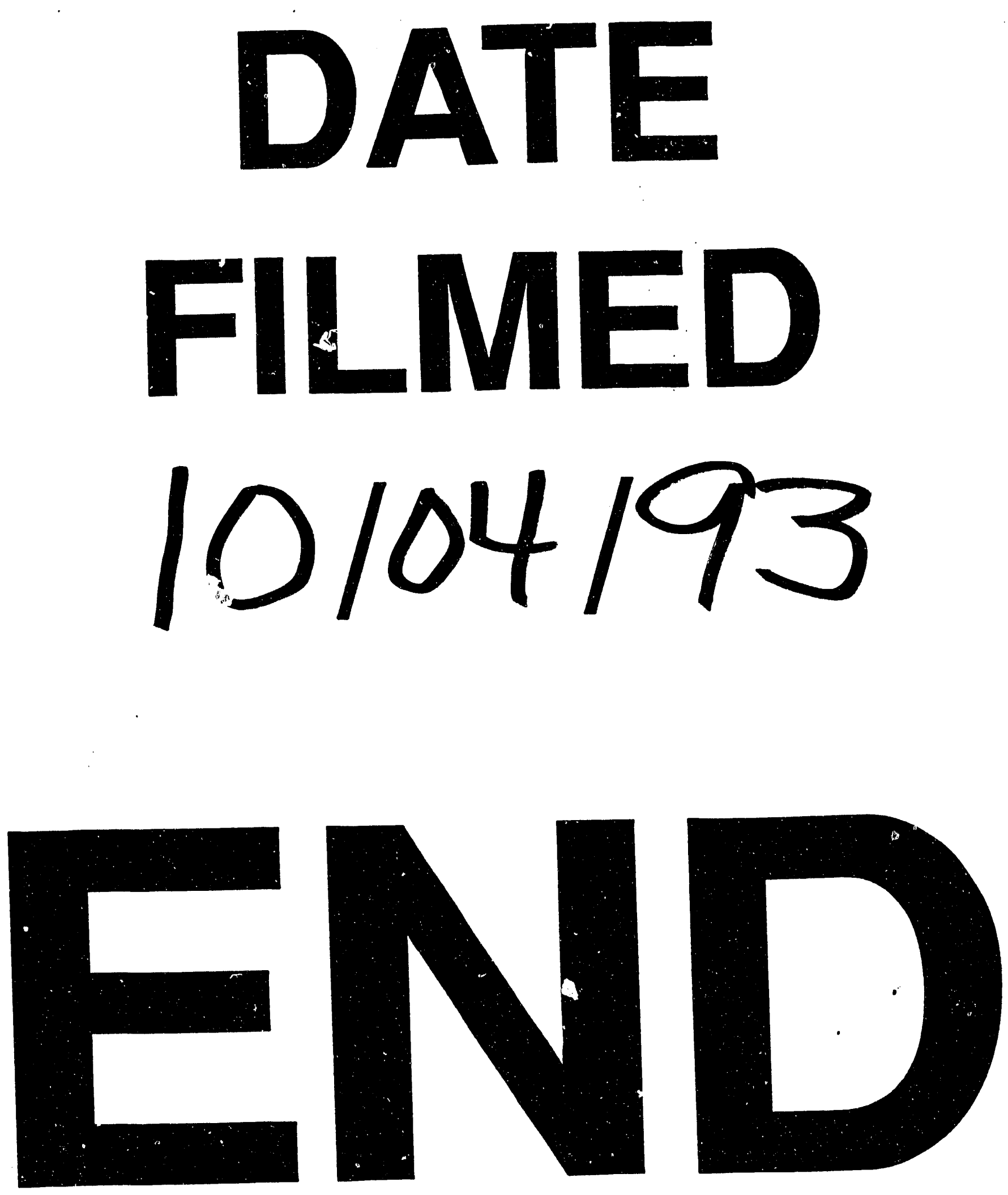
